\title{
Ranking regular seasons in the NBA's Modern Era using grey relational analysis
}

\author{
Sean Pradhan ${ }^{\mathrm{a}, \mathrm{b}, *}$ \\ ${ }^{a}$ Department of Sport Management, University of Michigan, Ann Arbor, MI, USA \\ ${ }^{\mathrm{b}}$ Center for Sport Marketing Research (C-SMAR), University of Michigan, Ann Arbor, MI, USA
}

\begin{abstract}
In the last few decades, the sports world has seen the precipitous rise of data-driven player analysis methods across many professional sports. In light of these advents to the field, the current paper offers a novel application of a multi-criteria classification scheme developed within the scholarly literature, that being: grey relational analysis (GRA), to the milieu of professional sports. Specifically, this technique is utilized in the context of the National Basketball Association (NBA) to rank regular seasons during the Modern Era (i.e., since the 1979-80 season, after the merger between the NBA and ABA) through the use of a constellation of statistics. A sample of 100 seasons initially classified by player efficiency rating (PER) were examined using GRA. Findings from the present study illustrate that Stephen Curry's recent MVP campaign during the 2015-16 season for the Golden State Warriors was the top ranked overall regular season out of those sampled in the Modern Era. The use of GRA is compared to current popular indicators for player evaluation and efficiency. Future directions and implications for professional sports are discussed.
\end{abstract}

Keywords: Player analytics, grey relational analysis (GRA), National Basketball Association (NBA), ranking, Modern Era

\section{Introduction}

The primary aspiration for virtually all clubs in the many team sports is victory. As succinctly stated by former New York Jets head coach and current football analyst for ESPN, Herman Edwards: "you play to win the game" (Yoder, 2012). While this goal may be simple in and of itself, there are many barriers that each team faces, such as privations in financial resources, deficiencies in talented players, or an inability to attract rising stars from the free agency market to a team's locality. Accordingly, the sports world has seen a surplus of teams plagued by these factors. However, with the recent and quite rapid economic expansion as witnessed through the escalation in television deals throughout the professional sports leagues and ensuing upsurges in salary caps as well as discrepancies in athlete talent, sports

\footnotetext{
*Corresponding author: Sean Pradhan, Department of Sport Management, University of Michigan, Ann Arbor, MI 48109 USA. Tel.: +1 734647 0945; Fax: +1 734647 2808; E-mail: seanprad@umich.edu.
}

analytics has emerged as a pioneering field that has sought to resolve such issues for teams. With tactics, such as moneyball and sabermetrics, used in various domains, (Mason and Foster, 2007), the quantitative analysis of sports has allowed teams to not only maximize player performance while keeping in mind any hindrances attributable to a salary cap, but has also led to many teams succeeding in their respective sports. Some prominent cases of such flourishing applications of analytics include many from Major League Baseball (MLB), such as the Oakland Athletics, Boston Red Sox, and Houston Astros among others.

Although sports analytics has been embraced by many within the sports industry (i.e., teams and corporations), the body of scholarly research on this matter has been limited. In addition, not all teams in the various professional sports leagues have accepted such analysis as the standard as a means to contribute or enhance the direction of player operations. For instance, a plethora of skeptics within the industry remain apprehensive on the viability of data-driven 
player analysis, such as within the National Basketball Association (NBA). While some teams like the Dallas Mavericks, Houston Rockets, Philadelphia 76ers, and San Antonio Spurs have vigorously invested in these analytic resources (Pelton, 2015), there still lie many who have not fully adopted statistical applications in player evaluations. Bearing these notions in mind, the current study aims to harness and apply previously established methods of analysis, founded within scholarly research, to the quantitative assessments of players in order to draw practical implications for the sports industry.

\section{Intentions}

In light of the dearth of player analysis in the NBA, the current study intends to offer a unique contribution to the field of sports analytics by providing a classification scheme of performance through the sampling of current and former athletes from the NBA. Using a theoretically validated technique prominently used in engineering (i.e., grey relational analysis [GRA]), we present an innovative application of this method as well as a bridge between theory itself (i.e., in this case grey systems theory, the conceptual underpinning behind GRA) and practice within the sports industry. In the present context, we aim to make use of player statistics as the criteria in determining the most successful regular season achieved by an NBA player in the Modern Era. The proposed utilization of the GRA as a player evaluation system has vast contributions to the field of not only sports analytics, but also hierarchal multi-criteria decision making (MCDM) applied in engineering.

The main contributions of the current study are two-fold. This study intends to (a) provide an extension of GRA within a unique context in the analysis of players and (b) propound a novel technique for practitioners to employ in determining the efficiency of both current and prospective players. These contributions can potentially fuel advancements in scouting methods, both on an amateur and professional level, wherein teams can make better judgments concerning player acquisitions. Moreover, these outcomes may even aid in player salary negotiations for teams, in which clubs can utilize MCDM techniques, such as GRA, to make comparisons between similar players and offer fair and more well-informed contracts based on not only the market-level of compensation, but also performance.

\section{Grey relational analysis}

Grey systems theory was first developed by Deng (1982) to describe the process of studying problems when only partially known information is accessible within a limited sample, conditions often common to practical, real-world issues (Liu and Lin, 2010). Grey systems theory posits that through the procurement, organization, and analysis of such available data, research can better solve problems utilizing various criteria (Deng, 1982). The process of GRA was conceived by Deng $(1982,1989)$ as a means to aid in the MCDM based on a series of apparent characteristics within a grey system, in reference to the concept of a black box wherein information is known (white) or unknown (black). In other words, grey information takes into consideration both knowns and unknowns within a system and through the use of GRA seeks to quantify performance using a matrixderived grade based on available data (Deng, 1982). The GRA technique has been successfully applied in scores of research within engineering, such as in laser cutting and optics (Chen et al., 2011), neural networking models (Lai et al., 2005), and electrical discharge machining processes (EDM; Lin and Lin, 2002).

Deng $(1982,1989)$ stipulated a series of steps within GRA in order to calculate grey relational grades (i.e., numerical scores signaling the influence that specific factors have on a system; Yu et al., 2011) based on sampled data. To be specific, Deng outlined five main steps in order to normalize an assembly of data and convert such figures into grey relational grades to generate a ranking system in determining the most influential, or highest performing, factor. To begin with, data $(x)$ are first arranged in a comparison matrix based upon a particular number of performance indicators $(n)$ that are to be contrasted against one another $(m)$.

$$
\left[\begin{array}{l}
x_{m}(n) x_{m}(n) \ldots x_{m}(n) \\
x_{m}(n) x_{m}(n) \ldots x_{m}(n) \\
x_{m}(n) x_{m}(n) \ldots x_{m}(n)
\end{array}\right]
$$

Subsequently, a referential series point $\left(x_{0}\right)$ is selected based upon the aim for the specific performance indicator. On one hand, if the ideal target outcome for such an indicator aims for those of higher values, then the highest value in the comparison matrix group is selected as the referential series point. On the other hand, if lower values are indicative of better performance, then the lowest series value is 
chosen as the reference point. Following this, the data from the comparison matrix are normalized by utilizing appropriate factor type calculations that obtain difference scores between observed values $\left(x_{i}\right)$ and referential series points. Benefit type factor calculations are conducted on observed data for a given indicator $(k)$ that aim for higher values to produce a grey relational degree $\left(x_{i}^{*}[k]\right.$; i.e., a measure of similarity between a series of data; Lo et al., 2005).

$$
x_{i}^{*}(k)=\frac{x_{i}(k)-\min x_{0}(k)}{\max x_{0}(k)-\min x_{0}(k)}
$$

Indicators that seek lower values for better performance are subjected to the defect type factor calculation in computing these relational degrees.

$$
x_{i}^{*}(k)=\frac{\max x_{i}(k)-x_{i}(k)}{\min x_{i}(k)-\max x_{i}(k)}
$$

The grey relational degrees are then transformed into difference scores $\left(\Delta x_{i}\right)$ to obtain the absolute distance between the referential series and observed data point.

$$
\Delta x_{i}(k)=\left|x_{0}(k)-x_{i}(k)\right|
$$

Distance metrics are then converted to grey relational coefficients $\left(\xi_{i}[k]\right.$; i.e., values signaling the association between the desired, or idealized, and actual sampled data; Lin, 2004) using the maximum $(\Delta \max )$ and minimum $(\Delta \mathrm{min})$ referential distance points multiplied by a selected distinguishing coefficient (i.e., a value $p$ between 0 and 1, most commonly set to 0.5; Das et al., 2016; Ecer and Boyukaslan, 2014; Kuo et al., 2008; Sakinç, 2014; Yeh and Lu, 2000).

$$
\xi_{i}(k)=\frac{\Delta \min +p \Delta \max }{\Delta x_{i}(k)+p \Delta \max }
$$

Ultimately, the grey relational grade $\left(r_{i}\right)$ is computed by summing each indicators' coefficient scores within a group $(\mathrm{w}[\mathrm{k}])$ and dividing by the proportion of the number of indicators in a group to the total number of indicators used in the analysis $(\xi[k])$.

$$
r_{i}=\sum[\mathrm{w}(\mathrm{k}) \xi(k)]
$$

After obtaining these relational grades, the data are then ranked from greatest to least to produce the GRA classification scheme, providing an indication of the factor reflecting the best performance in a sampled system.

\subsection{Grey relational analysis in sports}

While research directly employing GRA in sports is relatively scant, several scholars have attempted to do so. For example, Huang et al. (2006) investigated the competitive abilities of NBA teams from both the Eastern and Western Conferences using performance information (e.g., field goal, free throw, assist, rebound, steal, block, foul rates, and the like) obtained during the 2003-04 season. Using a sample that only included teams that made the playoffs that year, the results from Huang et al.'s (2006) study revealed that the GRA analysis correctly classified approximately $81 \%$ of the playoff teams (i.e., 13 out of 16 possible) using a total of merely nine evaluation criteria. Although the authors may have been limited by the usage of select criteria, their findings speak to the feasibility of applying GRA to appraise the potential for not only NBA teams, but also players within the league given many overlapping performance characteristics, regardless of a lack of available data.

Later research by Chen et al. (2010) examined similar notions to those studied by Huang and colleagues (2006). The authors of this study evaluated the performance of teams in the context of the National Football League (NFL), utilizing a series of performance and managerial efficiency indicators. In doing so, Chen et al. (2010) found that the GRA was able to accurately classify about $92 \%$ of playoff teams (i.e., 11 out of 12 possible) in the NFL during the 2005 season with only six performance attributes (e.g., points scored, points allowed, offensive yards gained, defensive yards allowed, defensive interceptions, kickoff return attempts). Specifically, the researchers of this study correctly categorized approximately $83 \%$ of playoff bound teams in the American Football Conference (AFC) and $100 \%$ of those in the National Football Conference (NFC), further supporting the use of GRA in sports settings.

In more recent years, the empirical research employing GRA has commonly been applied in the financial analysis of various sport clubs, particularly within international soccer. Case in point, Ecer and Boyukaslan (2014) examined the financial performance of Turkish teams publicly traded on the Istanbul Stock Exchange (Borsa Istanbul) using a collection of financial ratios. The results of their study conceded that out of the surveyed clubs, Fenerbahçe Spor Kulübü was the most fiscally successful publicly-traded soccer club within the Turkish Süper Lig. Subsequent research by Sakinç (2014) as well as Oral (2016) utilizing GRA to similarly 
analyze financial performance of such Turkish soccer clubs provided evidence to support the useful application of GRA in sports and sustained the results obtained by Ecer and Boyukaslan (2014).

In view of the literature utilizing GRA to measure performance within engineering on mechanized efficiency as well as in professional sports and directly in an NBA setting on holistic team evaluations, the current study provides an application of GRA in player analysis. Using previous seasons from both former and active NBA players, we develop a ranking system to categorize performance based on a collection of criteria derived from player statistics. In the next sections, we describe the obtained data, apply the GRA to the data, and then illustrate the conclusions drawn from our analysis in the context of professional sports.

\section{Data}

Data for the present experiment were obtained from Basketball-Reference (2016). For preliminary consideration and practical reasons, we selected the top 100 regular seasons based on player efficiency rating (PER) to use for our analysis. However, data was limited to players from the Modern Era, specifically after the merger between the NBA and the American Basketball Association (ABA) in 1979 and following the implementation of the 3-point line on the court during the 1979-80 season. Thus, data for this study were attained for players who participated following the 1979-80 NBA season spanning until the most recent completed NBA season (i.e., the 2015-16 season).

The evaluation criteria that we chose were split into two main categories: traditional and advanced statistics. Traditional figures included both games played (GP) and games started (GS). Furthermore, we also included the following traditional per game (i.e., averaged over the number of games played) statistics comprising of minutes played (MP), field goals made, (FGM), field goals attempted (FGA), field goal percentage (FG\%), 3-point field goals made (3PM), 3-point field goals attempted (3PA), 3 -point field goal percentage (3P\%), two-point field goals made (2PM), two-point field goals attempted (2PA), two-point field goal percentage ( $2 \mathrm{P} \%$ ), effective field goal percentage (eFG\%), free-throws made (FT), free-throws attempted (FTA), free-throw percentage (FT\%), offensive rebounds (ORB), defensive rebounds (DRB), total rebounds (TRB), assists (AST), steals (STL), blocks (BLK), turnovers (TO), personal fouls (PF), and points (PTS). In addition, during seasons in which there was a labor strike, or lockout, that ceased play and shortened the number of regular season games (e.g., during the 1998-99 and 2011-12 seasons), we adjusted GP and GS to percentages (i.e., GP\% and GS\%, respectively) for all player data to account for any incongruities and bias toward the nature of the season.

Advanced statistics consisted of the following figures: true shooting percentage (TS\%), 3-point attempt rate (3PAr), free-throw attempt rate (FTr), offensive rebound percentage (ORB\%), defensive rebound percentage (DRB\%), total rebound percentage (TRB\%), assist percentage (AST\%), steal percentage (STL\%), block percentage (BLK\%), turnover percentage (TO\%), usage percentage (USG\%), offensive win shares (OWS), defensive win shares (DWS), total win shares (WS), win shares per 48 minutes (i.e., a full non-overtime NBA game; WS/48), offensive box plus/minus (OBPM), defensive box plus/minus (DBPM), box plus/minus (BPM), value over replacement player (VORP) as well as PER. The categorization of traditional and advanced metrics was defined by conditions set by Basketball-Reference (2016). Taken together, a total of 45 performance metrics, 25 traditional and 20 advanced, were used for this study. Table 1 offers a list of all criteria and the ideal direction in which higher performance on the metric would be indicated. All raw data and the player seasons used for the present study can be found in Tables A1 and A2 located in the Appendix.

\section{Applying grey relational analysis to the obtained data}

The GRA was carried out on the obtained data displayed in Table A1. Following the steps outlined by Deng (1982, 1989), the obtained data served as the comparison matrix. We then selected the idealized statistics within the sample for referential series points and normalized the data using benefit or defect type factor computations where appropriate. These calculations are displayed in Tables A3 and A4. Subsequently, these grey relational degrees were converted to distance scores (see Tables A5 and A6) and then transformed into grey relational coefficients (see Tables A7 and A8), using the respective procedures. From these coefficients, we then produced the grey relational grades. However, we calculated the relational grades for both traditional as well as advanced 
Table 1

Player statistics used in performance evaluation

\begin{tabular}{|c|c|c|}
\hline Performance Criteria & Code & Ideal Direction \\
\hline \multicolumn{3}{|l|}{ Traditional } \\
\hline Games played percentage & $\mathrm{GP} \%$ & Higher \\
\hline Games started percentage & GS\% & Higher \\
\hline Minutes played & MP & Lower \\
\hline Field goals made & FGM & Higher \\
\hline Field goals attempted & FGA & Lower \\
\hline Field goal percentage & FG\% & Higher \\
\hline 3-point field goals made & $3 \mathrm{PM}$ & Higher \\
\hline 3-point field goals attempted & 3PA & Higher \\
\hline 3-point field goal percentage & $3 \mathrm{P} \%$ & Higher \\
\hline Two-point field goals made & 2PM & Higher \\
\hline Two-point field goals attempted & $2 \mathrm{PA}$ & Lower \\
\hline Two-point field goal percentage & $2 \mathrm{P} \%$ & Higher \\
\hline Effective field goal percentage & $\mathrm{eFG} \%$ & Higher \\
\hline Free-throws made & FT & Higher \\
\hline Free-throws attempted & FTA & Higher \\
\hline Free-throw percentage & FT\% & Higher \\
\hline Offensive rebounds & ORB & Higher \\
\hline Defensive rebounds & DRB & Higher \\
\hline Total rebounds & $\mathrm{TRB}$ & Higher \\
\hline Assists & AST & Higher \\
\hline Steals & STL & Higher \\
\hline Blocks & BLK & Higher \\
\hline Turnovers & TO & Lower \\
\hline Personal fouls & PF & Lower \\
\hline Points & PTS & Higher \\
\hline \multicolumn{3}{|l|}{ Advanced } \\
\hline True shooting percentage & $\mathrm{TS} \%$ & Higher \\
\hline 3-point attempt rate & 3PAr & Higher \\
\hline Free-throw attempt rate & FTr & Higher \\
\hline Offensive rebound percentage & ORB $\%$ & Higher \\
\hline Defensive rebound percentage & DRB $\%$ & Higher \\
\hline Total rebound percentage & TRB $\%$ & Higher \\
\hline Assist percentage & AST\% & Higher \\
\hline Steal percentage & STL $\%$ & Higher \\
\hline Block percentage & BLK\% & Higher \\
\hline Turnover percentage & TO\% & Lower \\
\hline Usage percentage & USG\% & Lower \\
\hline Offensive win shares & OWS & Higher \\
\hline Defensive win shares & DWS & Higher \\
\hline Total win shares & WS & Higher \\
\hline Win shares per 48 minutes & WS/48 & Higher \\
\hline Offensive box plus/minus & OBPM & Higher \\
\hline Defensive box plus/minus & DBPM & Higher \\
\hline Box plus/minus & BPM & Higher \\
\hline Value over replacement player & VORP & Higher \\
\hline Player efficiency rating & PER & Higher \\
\hline
\end{tabular}

indicators in order to compare player performance from these two perspectives, as depicted in Table A9. Ultimately, we converted these grades into the overall grey relational grade and then ranked these figures to produce the classification scheme. The next section discusses the results from the GRA.

\subsection{Results}

The results from the GRA indicated that traditional indicators of performance contributed slightly more to the overall relational grade than did advanced criteria based upon the obtained grey relational grades $\left(r_{i \mathrm{TRAD}}=52.98 \%\right.$ vs. $\left.r_{i \mathrm{ADV}}=51.04 \%\right)$. Inspection of the final relational grades and ranking of the data in Table A9 illustrated that Stephen Curry's 2015-16 NBA regular season for the Golden State Warriors, in which he won the Most Valuable Player (MVP) Award that year (NBA, 2016), was the best overall season according to our performance criteria. His overall performance was followed by Michael Jordan's 1987-88 MVP season and 1988-89 campaign for the Chicago Bulls and Lebron James' 2012-13 and 2008-09 MVP seasons for the Miami Heat and Cleveland Cavaliers (NBA, 2016), respectively completing the top-5 regular seasons. Figure 1 provides a visual illustration of the top-10 NBA seasons as per the GRA analysis.

While Curry did have both the best overall and traditionally ranked season during the 2015-16 NBA year, Jordan's 1987-88 season was actually the top season ranked by the advanced criteria. Bearing this in mind, examination of the data indicated that there were minor differences in the rankings between the traditional and advanced indicators across the sampled seasons. However, these rankings produced by the grey relational grades were not statistically different from each other, as verified by a followup Wilcoxon Signed-rank test $(z=-0.31, p=0.76)$. Thus, this may suggest that the GRA classification scheme sufficiently fits the data and can inimitably and appropriately rank these seasons.

A Spearman's rank-order correlation was also conducted to examine the relationship between the rankings produced by traditional and advanced performance indicators. This correlation indicated that the rankings between the traditional and advanced indicators were significantly and positively related to each other, $r_{s}(100)=0.59, p<0.001$. Further analysis was performed comparing the ranking system produced from the GRA to statistics commonly used as benchmarks to indicate performance, such as PER and VORP. A Wilcoxon Signed-rank test illustrated that the ranks produced by the GRA did not significantly differ from ranks determined by both PER $(z=-0.22, p=0.83)$ and VORP $(z=-0.38, p=0.70)$, which may provide a signal of the GRA's utility as a reliable measure of player performance. While subsequent Spearman's rank-order correlation analyses did reveal significant positive relationships between the ranking system of the GRA and ranks derived from both PER $\left(r_{s}[100]=0.45, p<0.001\right)$ and VORP $\left(r_{s}[100]=0.67, p<0.001\right)$, the GRA nevertheless 


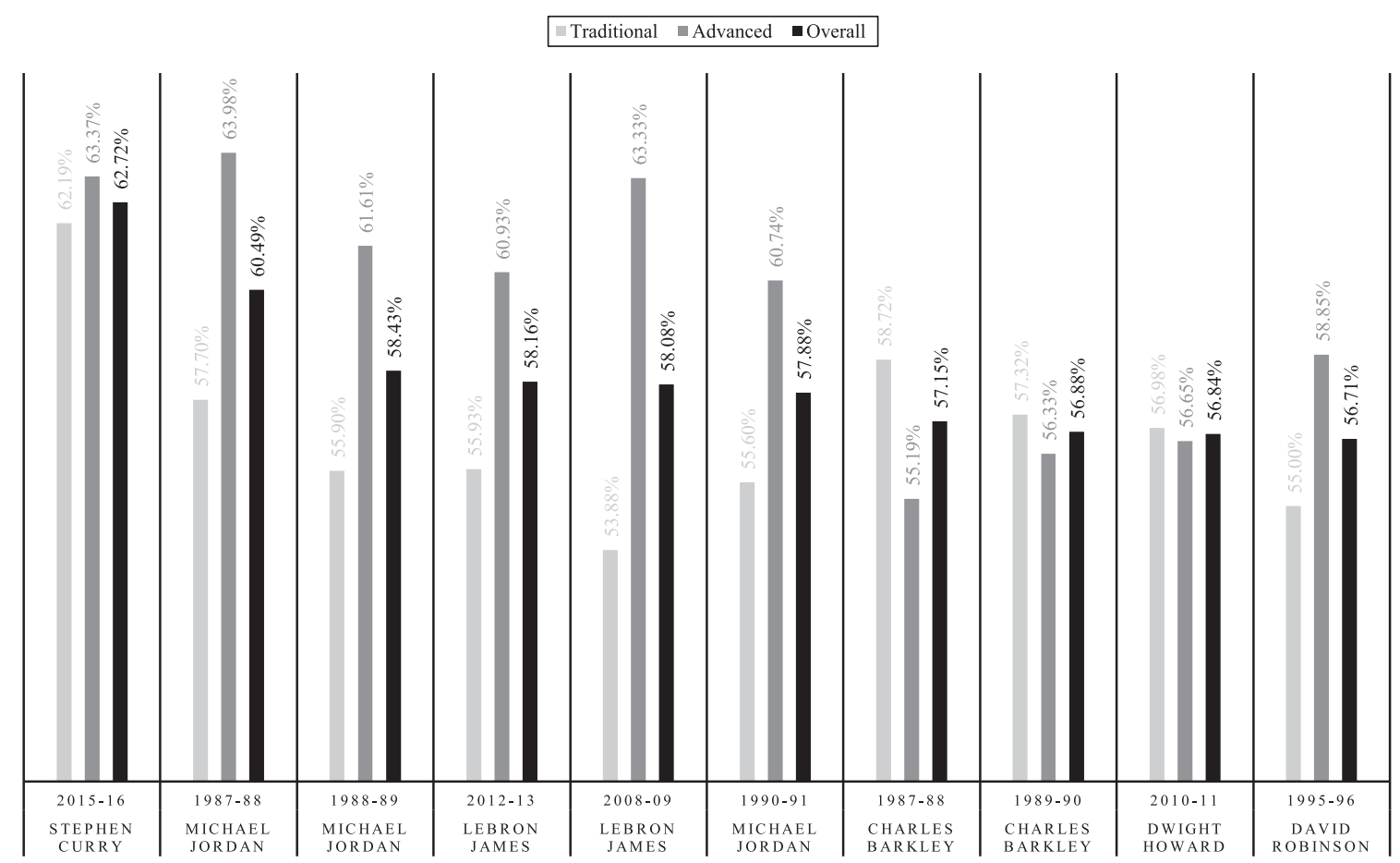

Fig. 1. Top-10 overall NBA seasons produced by the GRA. Grey relational grades computed from both traditional and advanced performance criteria are also included.

appears to be related but in certain manners, uniquely distinct from these commonly employed indicators of player performance.

\section{Discussion}

The present paper offers a novel approach of the GRA to the ranking of NBA players based on a series of both traditional and advanced performance indicators. Although Stephen Curry's 2015-16 season was the top ranked overall and traditional season according to the GRA, the findings from the rankings derived from the advanced statistics may speak to the importance of weighing various facets of performance in player rankings. That is, teams must be wary of relying on merely single indicators of performance and should analyze players holistically based upon the team's specific needs. Furthermore, the methods used in the current study also offer an efficient and unique way of evaluating player value. Due to the frequent and various unknowns surrounding players, the GRA method employs available known information (i.e., grey information) about a player (e.g., statistics) to come to optimal decisions concerning performance. In doing so, GRA can not only provide reliable and comparable assessments, as contrasted against methods such as PER or VORP in player analysis, but has also been shown to be applicable in a variety of contexts and oftentimes, noted as the more superior option in other MCDM situations (Kuo et al., 2008). Thus, GRA promotes a less biased assessment of players as well as a flexible approach to such analyses through the use of limited, available data.

While the present study may have converged toward a modern style of play within the NBA due to the arrival of the 3-point shot in present times given the scope of the research and limited by the use of PER as the initial sampling condition for high performance, our study nevertheless offers a number of directions for the industry of sports itself and future research. Taken together, the results display the viability of utilizing GRA in sports and demonstrate the value of analytics research in evaluating players. However, the current study does not discount the place and integral role that conventional techniques (e.g., traditional scouting) serve in the determination of rosters and player operations. Rather, this research informs the field by offering data-driven evidence to bolster these customs. Simply put, this research operates to produce techniques that will benefit teams from a performance standpoint by encouraging the pooling of resources drawn 
from both more traditional evaluations as well as analytic approaches. Practitioners can profit from this by harnessing our application of GRA in harmony with methods such as scouting to decisions involving not only the signing of prospective free agents during a certain offseason, but also the re-signing of current players.

The results of this research may also enlighten team executives in assessing and engaging in trades amongst other teams. Such GRA techniques may also allow teams to prepare for the drafting of potential players into the various professional sports leagues. Furthermore, our study may also justify the use of positional analysis in meeting specific team necessities (e.g., the need for proficient outside scorers via the 3-point shot in the NBA). In utilizing such positional analyses, teams can make use of data from the recent seasons from an assembly of potential players to examine their fit and even overall efficiency to the team's underlying weaknesses. Consequently, executives may be able to congregate stronger rosters that can compete for league championships on an annual basis.

The true potency of the current research lies within the analytical applicability to not simply a basketball context, but also to a vast array of sporting environments (e.g., baseball, football, soccer), as supported by previous work (Chen et al., 2010; Ecer and Boyukaslan, 2014; Huang et al., 2006; Oral, 2016; Sakinç, 2014). Taken together, our research offers a cutting-edge application of an established MCDM technique in the GRA to the realm of sports analytics. We hope to answer the demand and trend toward analytics as abody itself, bringing to light novel techniques that can be used to enhance competition in sports and give rise to the function of scholarly established procedures in applied industries.

\section{References}

Basketball-Reference, 2016. NBA \& ABA single season leaders and records for player efficiency rating. [online] Available at: http://www.basketballreference.com/leaders/per_season.html.

Chen, K.C., Huang, L.F., Hung, C.Y., Chen, Y.C., Wu, H.T. and Huang, W.K., 2010. Fight evaluation and managerial efficiency evaluation of NFL teams, Journal of Statistics and Management Systems 13(2), 309-325.

Chen, M.F., Ho, Y.S., Hsiao, W.T., Wu, T.H., Tseng, S.F. and Huang, K.C., 2011. Optimized laser cutting on light guide plates using grey relational analysis, Optics and Lasers in Engineering 49(2), 222-228.

Das, B., Roy, S., Rai, R.N. and Saha, S.C., 2016. Application of grey fuzzy logic for the optimization of $\mathrm{CNC}$ milling parameters for $\mathrm{Al}-4.5 \% \mathrm{Cu}-\mathrm{TiC}$ MMCs with multi-performance characteristics, Engineering Science and Technology 19(2), 857-865.

Deng, J.L., 1982 Control problems of grey systems, Systems \& Control Letters 1(5), 288-294.

Deng, J.L., 1989. Introduction to grey system theory, The Journal of Grey System 1(1), 1-24.

Ecer, F. and Boyukaslan, A., 2014. Measuring performances of football clubs using financial ratios: The grey relational analysis approach, American Journal of Economics 4(1), 62-71.

Huang, K.C., Huang, L.F., Lin, H.Y., Lin, S.C. and Kuo, J.C., 2006. Fight evaluation of NBA teams - Application of grey relational analysis, Journal of Information and Optimization Sciences 27(2), 481-498.

Kuo, Y., Yang, T. and Huang, G.W., 2008. The use of grey relational analysis in solving multiple attribute decision-making problems, Computers \& Industrial Engineering 55(1), 80-93.

Lai, H.H., Lin, Y.C. and Yeh, C.H., 2005. Form design of product image using grey relational analysis and neural network models, Computers \& Operations Research 32(10), 2689-2711.

Lin, C.L., 2004. Use of the Taguchi method and grey relational analysis to optimize turning operations with multiple performance characteristics, Materials and Manufacturing Processes 19(2), 209-220.

Lin, C.L., Lin, J.L. and Ko, T.C., 2002. Optimisation of the EDM process based on the orthogonal array with fuzzy logic and grey relational analysis method, The International Journal of Advanced Manufacturing Technology, 19(4), 271-277.

Liu, S. and Lin, Y., 2010. Grey systems: Theory and applications. Berlin, DE: Springer.

Lo, S.M., Hu, B.Q., Liu, M. and Yuen, K.K., 2005. On the use of reliability interval method and grey relational model for fire safety ranking of existing buildings, Fire Technology 41(4), 255-270.

Mason, D.S. and Foster, W.M., 2007. Putting Moneyball on ice? International Journal of Sport Finance 2(4), 206-213.

NBA, 2016. NBA MVP award winners. [online] Available at: http://www.nba.com/history/nba-mvp-award-winners/.

Oral, C., 2016. Financial performance evaluation of sport clubs traded in Borsa Istanbul by using grey relational analysis, International Journal of Economics and Finance 8(5), 293-299.

Pelton, K., 2015. The great analytics rankings. [online] ESPN. Available at: http://www.espn.com/espn/feature/ story//id/12331388/the-great-analytics-rankings.

Sakinç, İ., 2014. Using grey relational analysis to determine the financial performance of Turkish football clubs, Journal of Economics Library 1(1), 22-33.

Yeh, M.F. and Lu, H.C., 2000. Evaluating weapon systems based on grey relational analysis and fuzzy arithmetic operations, Journal of the Chinese Institute of Engineers 23(2), 211-221.

Yoder, M., 2012. Herm Edwards' 'Play To Win The Game' rant among best coach press conferences ever. [online] Huffington Post. Available at: http://www.huffingtonpost. com/2012/10/31/herm-edwards-best-coach-pressconference-video_n_2050422.html.

Yu, Z., Fung, B.C., Haghighat, F., Yoshino, H. and Morofsky, E., 2011. A systematic procedure to study the influence of occupant behavior on building energy consumption, Energy and Buildings 43(6), 1409-1417. 


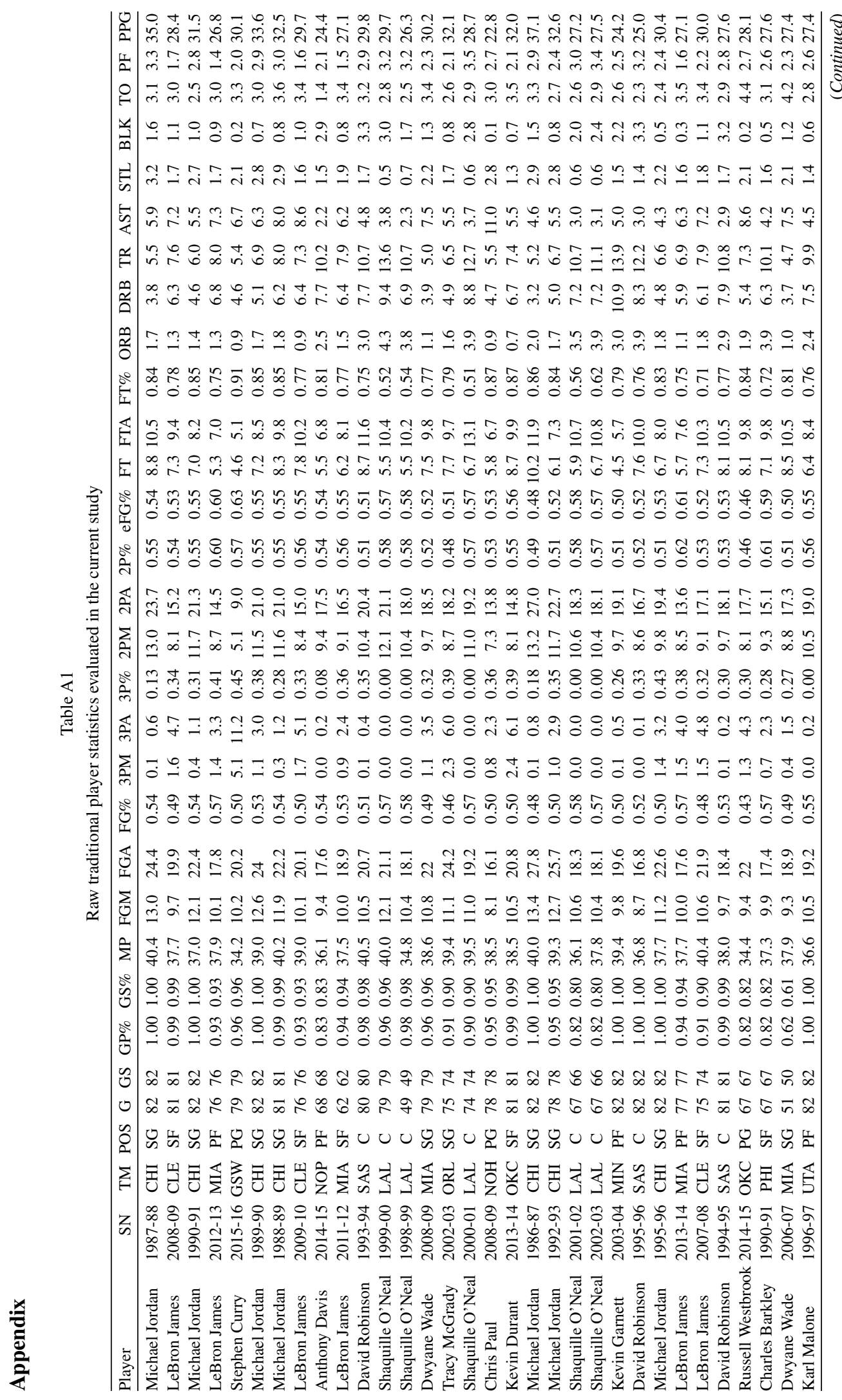




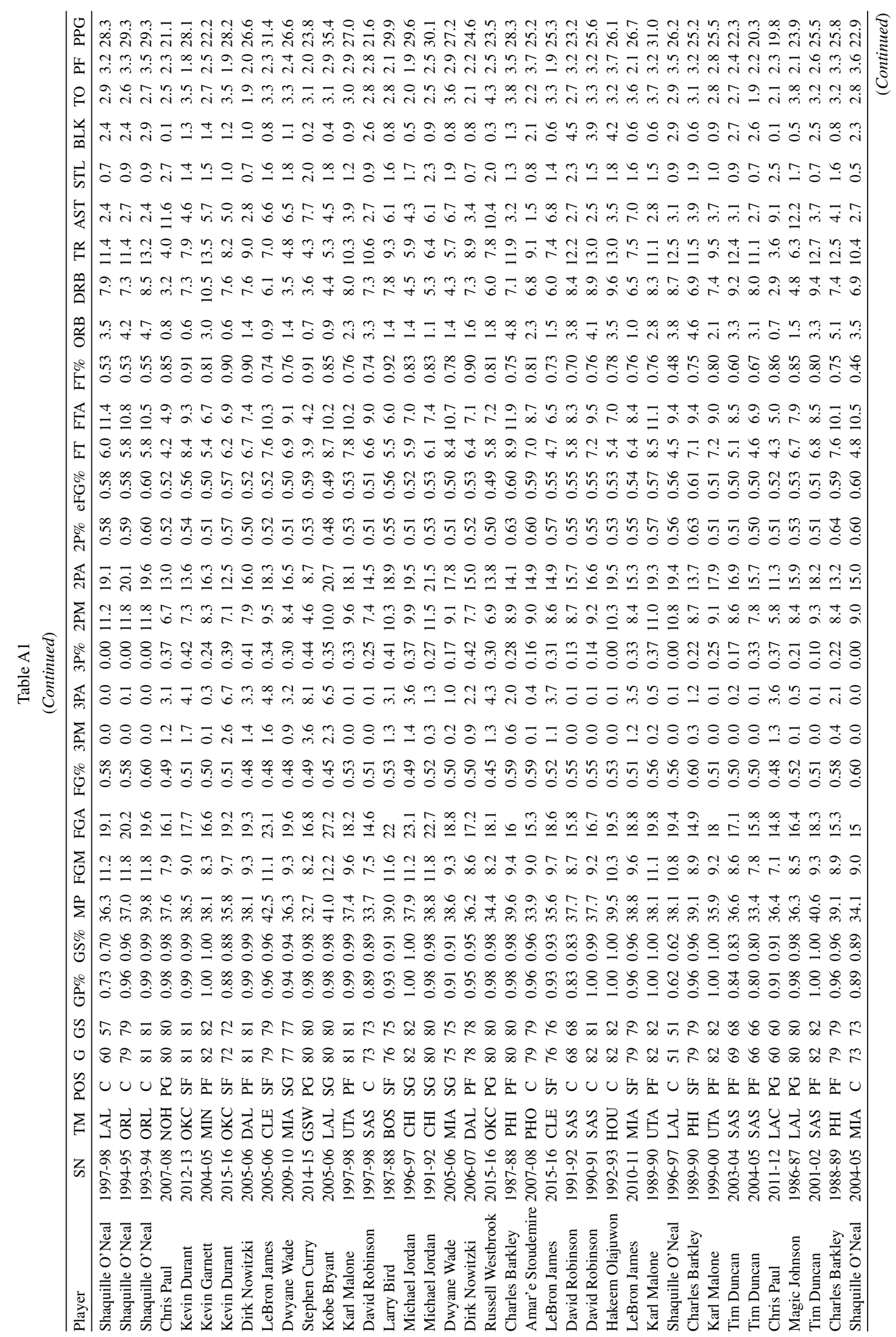




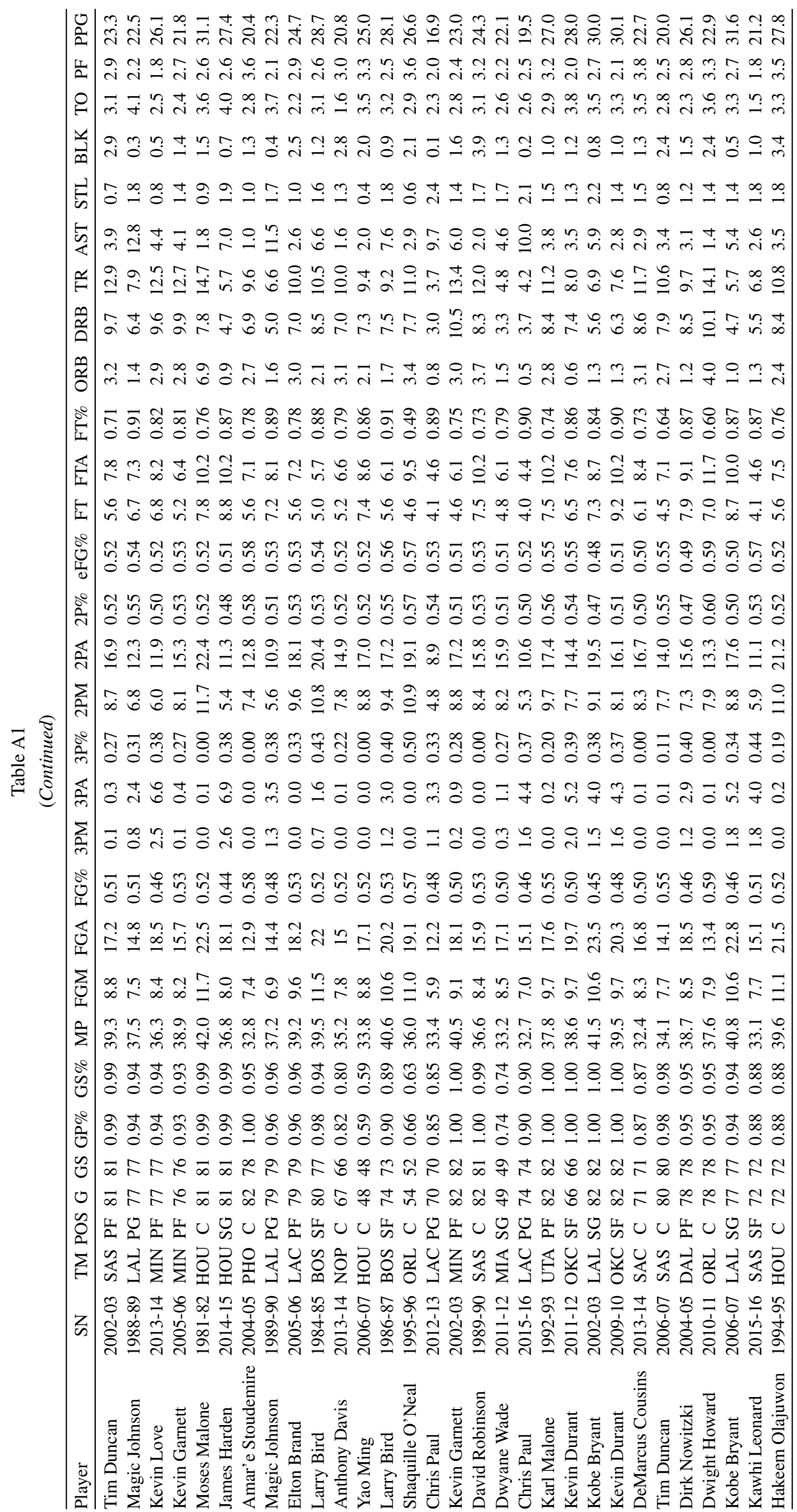




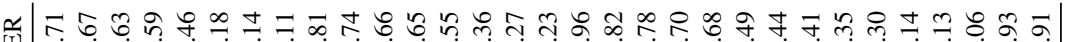

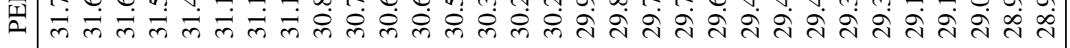

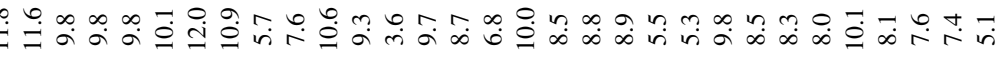

隹

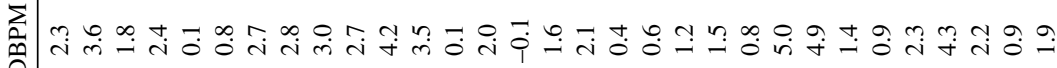

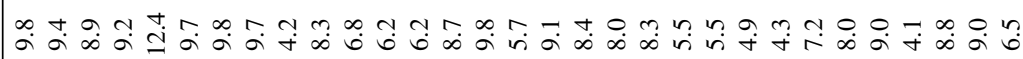

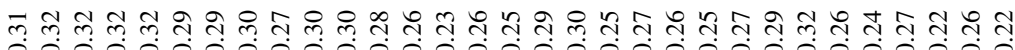

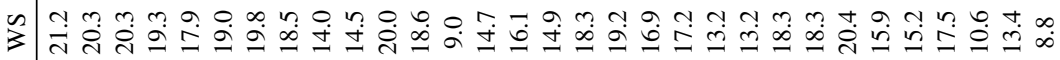

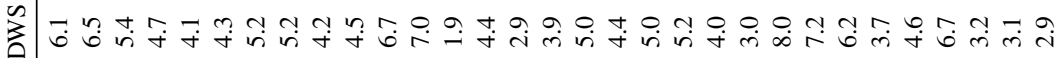

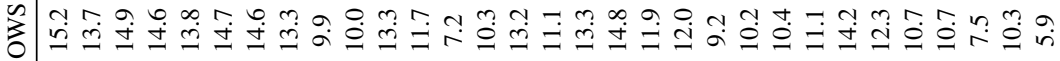

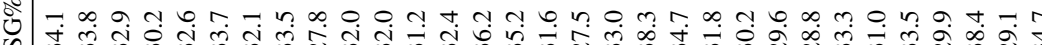

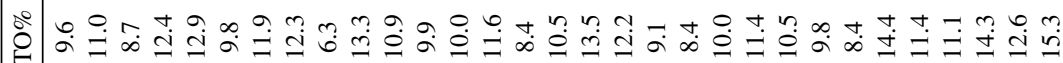

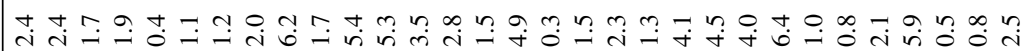

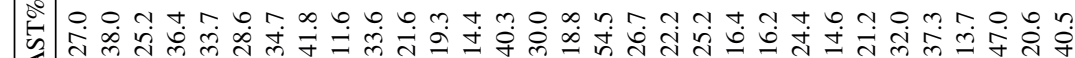

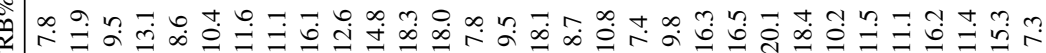

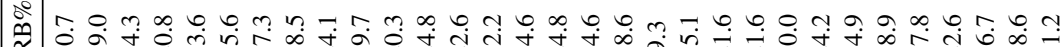

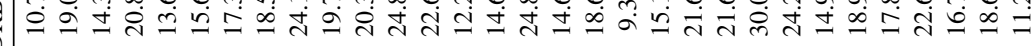

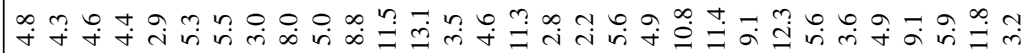

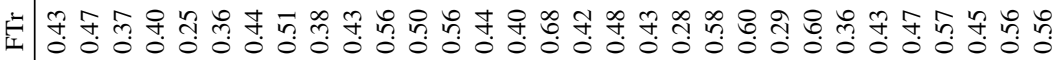

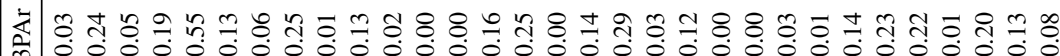

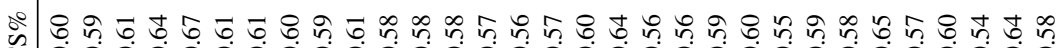

为

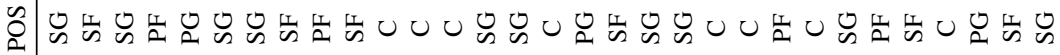

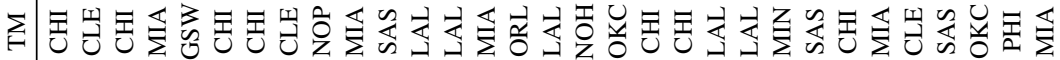

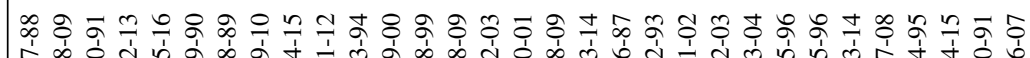

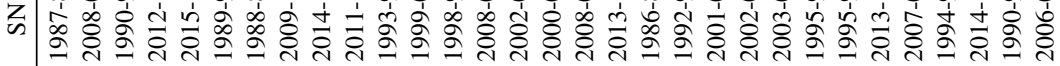

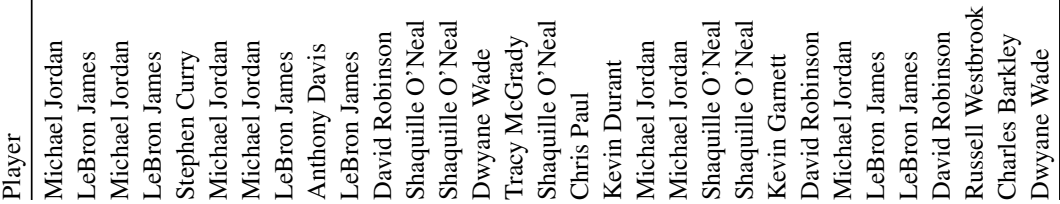


뼝ำ

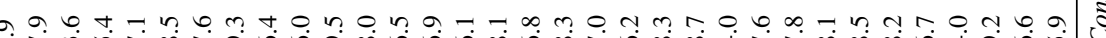
बे 光

0 궁

Әิ

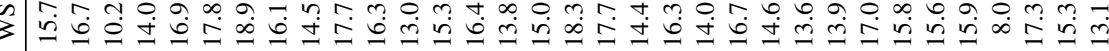

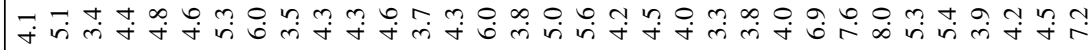

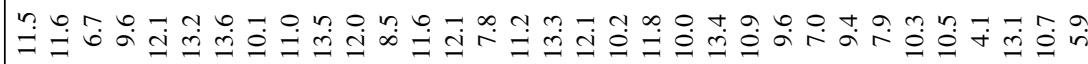

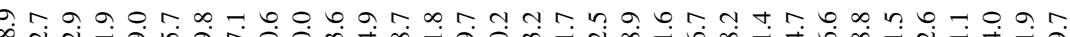

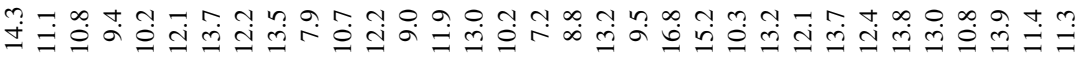

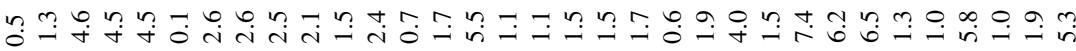

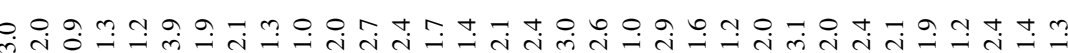

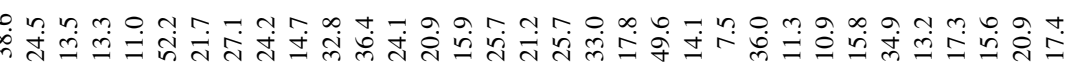

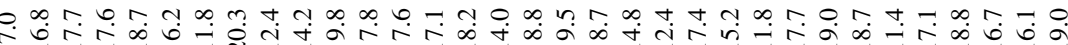

H.

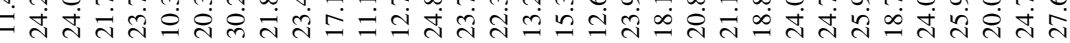

خ

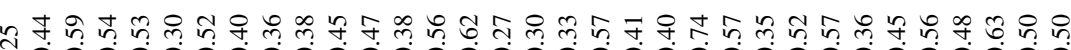

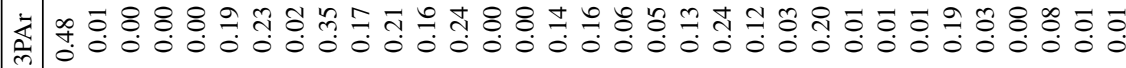

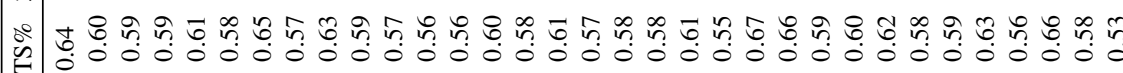

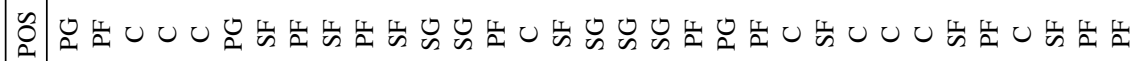

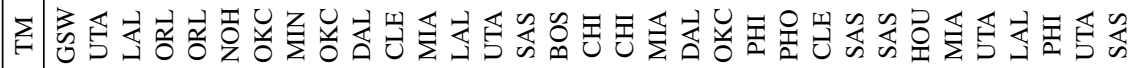

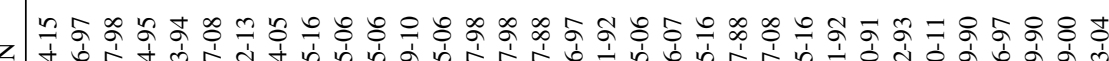

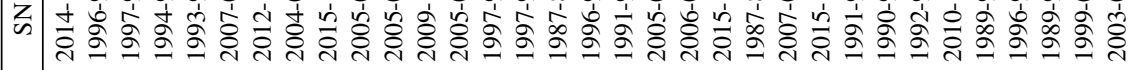

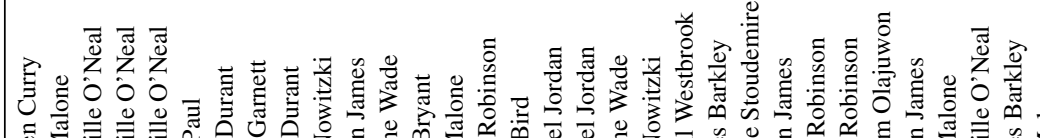




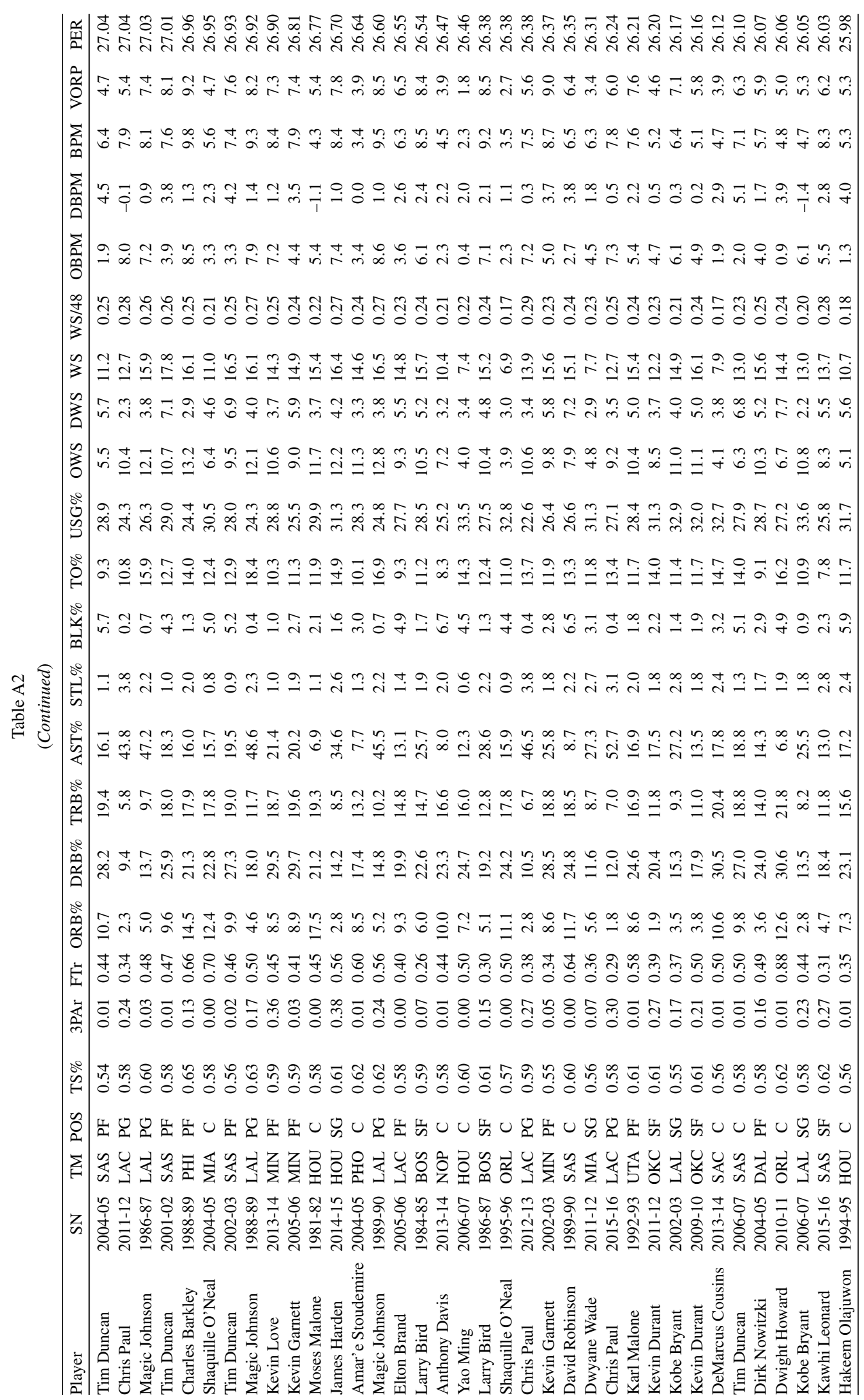




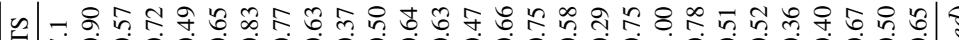

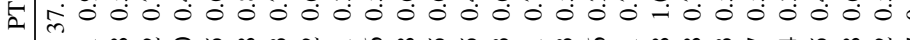

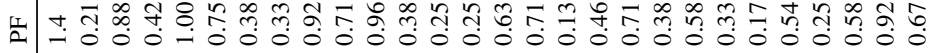

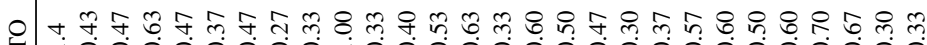
4 규요 ص भ

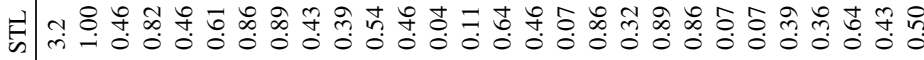

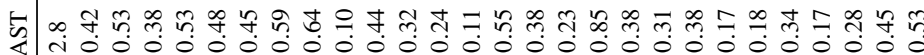

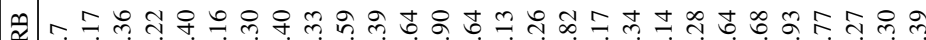

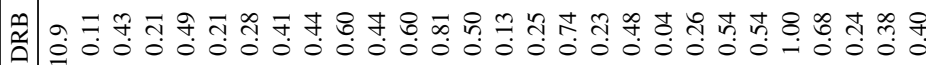

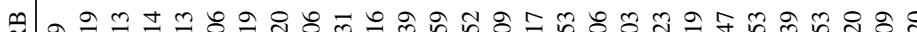
๙ै

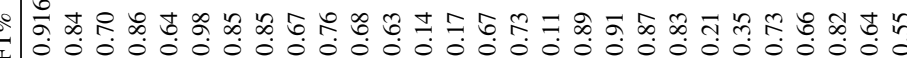

-

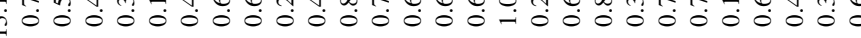

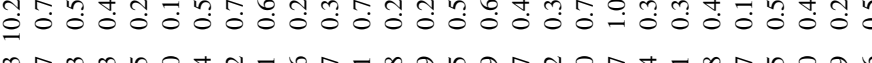

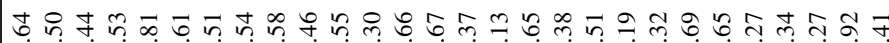

넘

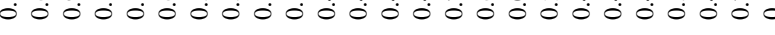

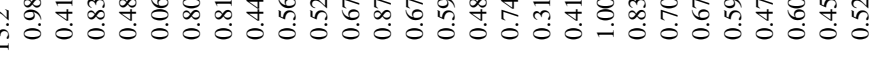

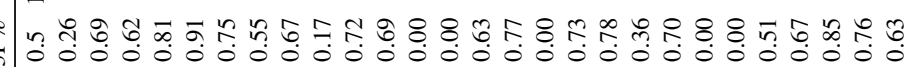

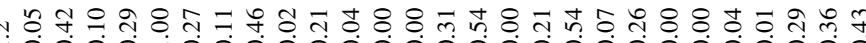
- ำ

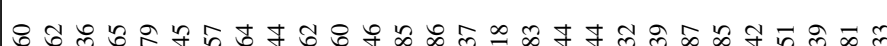

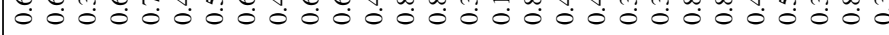
ก สิ

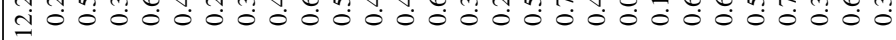

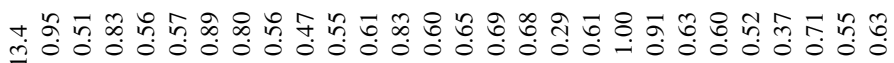

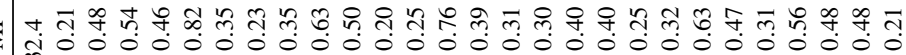
\& \&

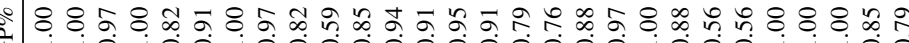

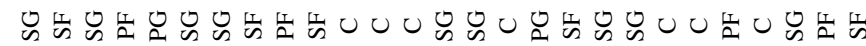

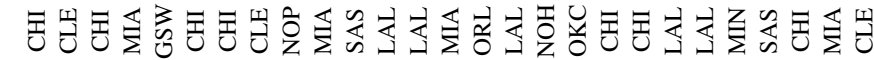
$\infty$ o

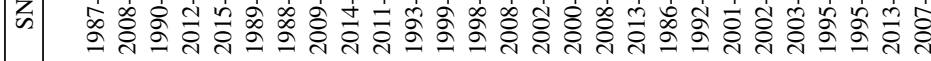
玨

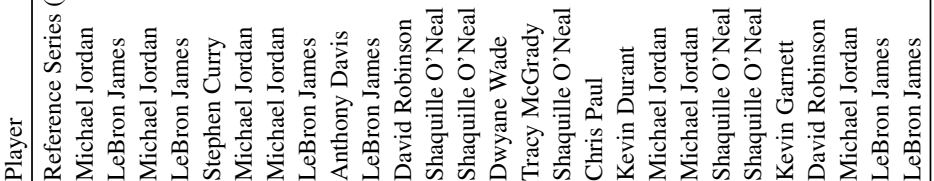


ص| L

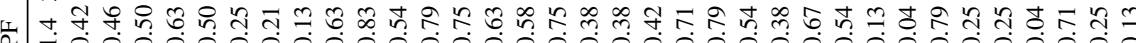
- 0000000000000000000000000000000000

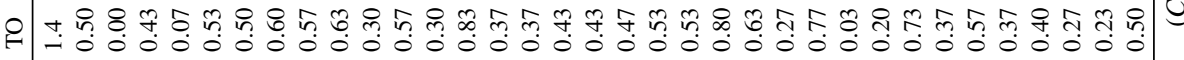

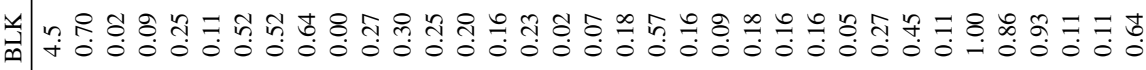

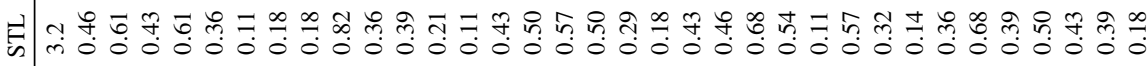

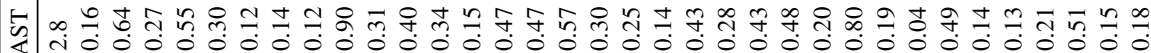

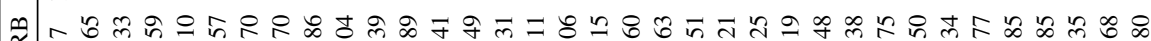

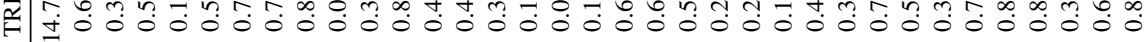

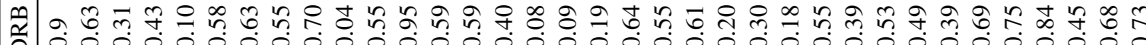

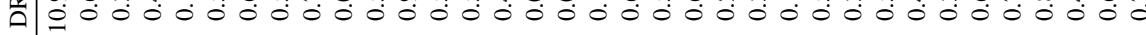

急

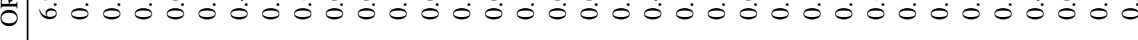

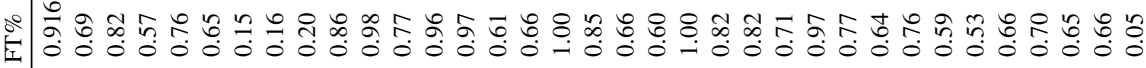

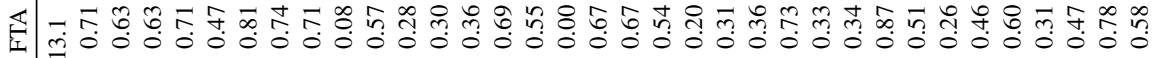

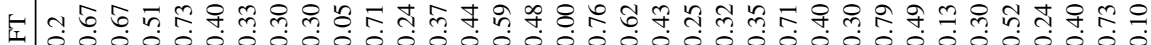
I 00000000000000000000000000000000000

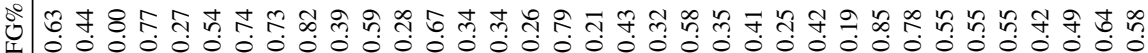

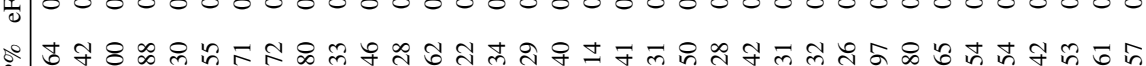

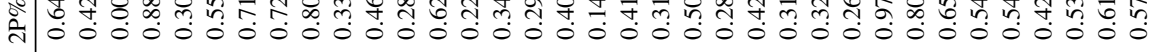

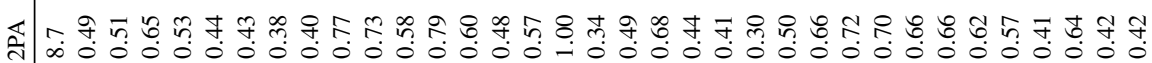

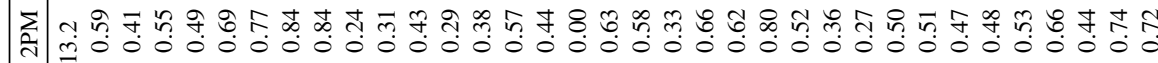

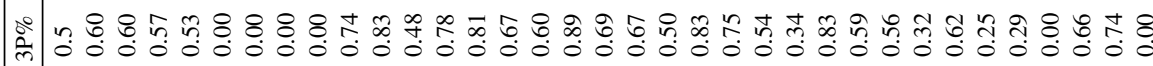

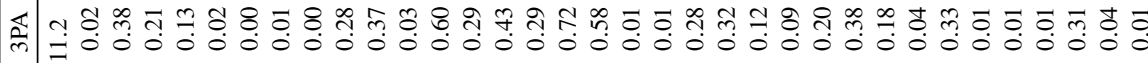

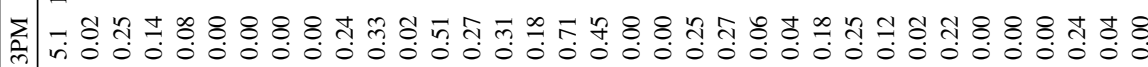

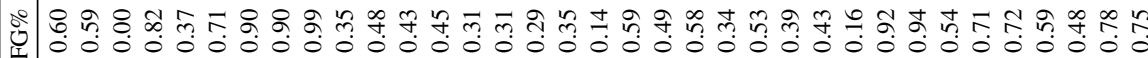

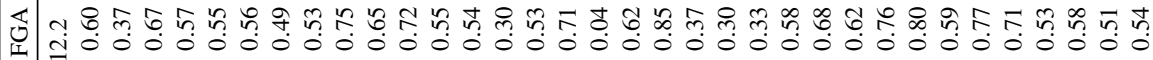

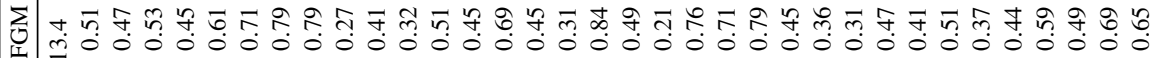

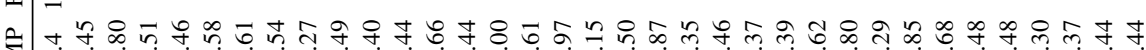

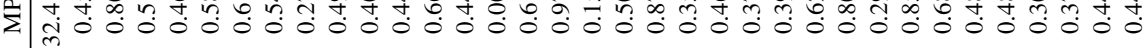

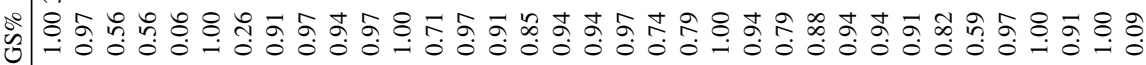

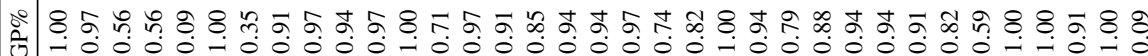

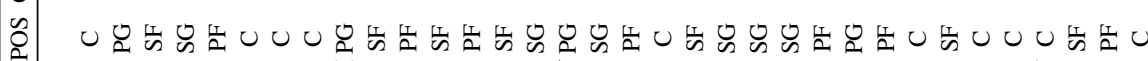

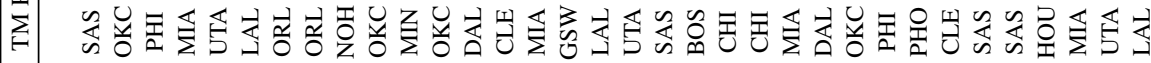

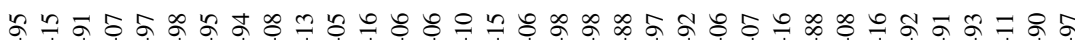

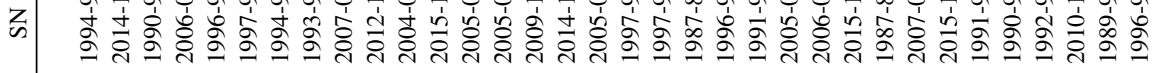
在

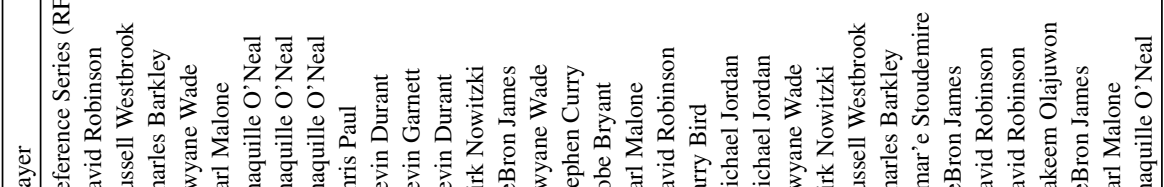

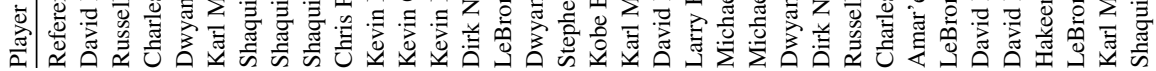




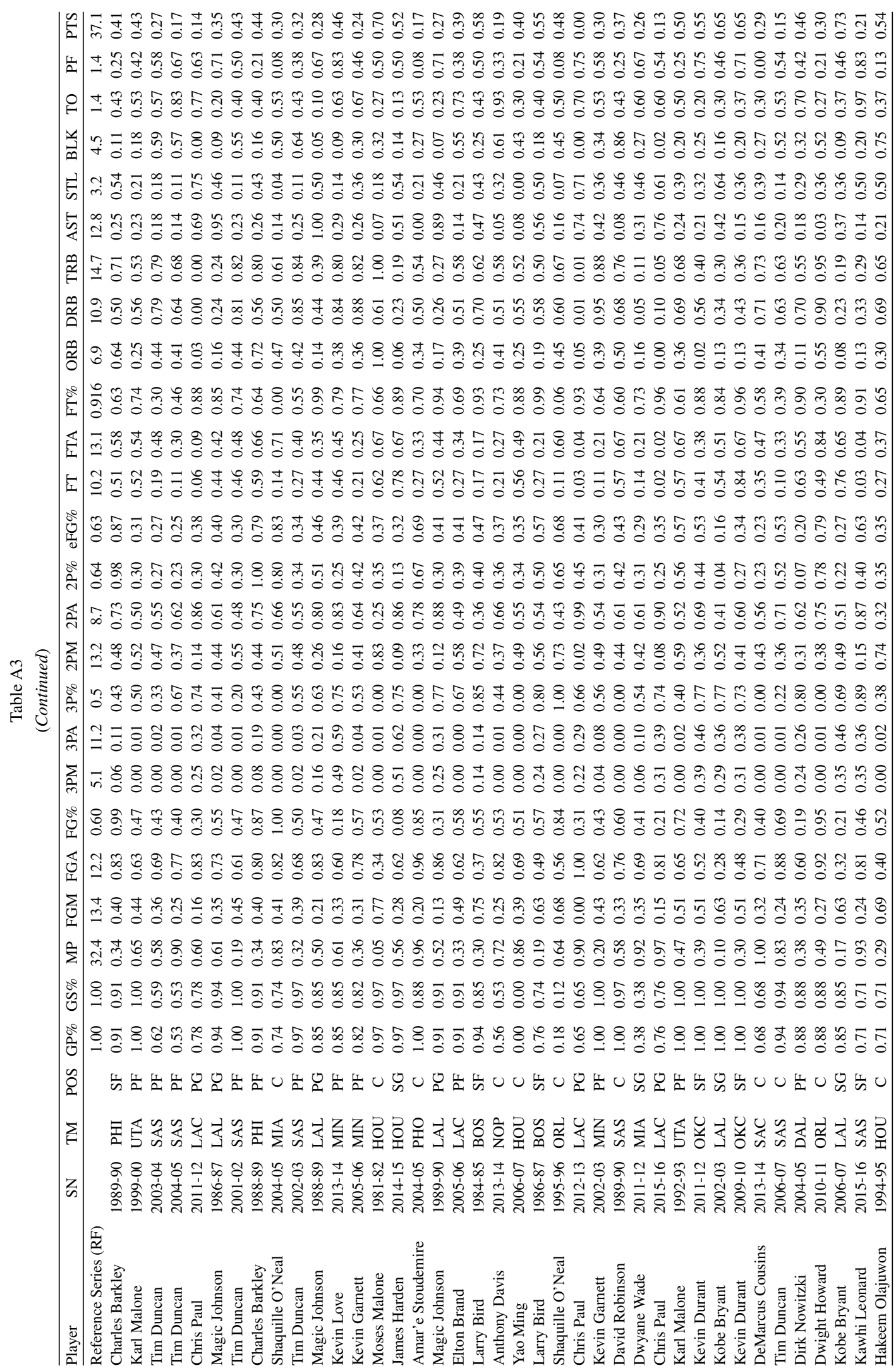




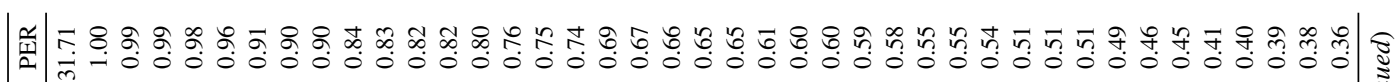

商

商

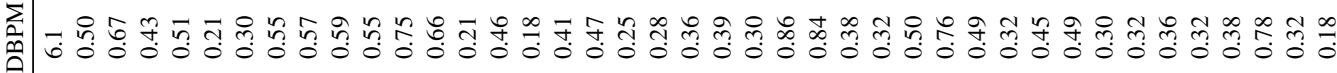

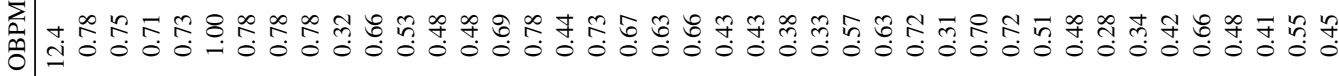

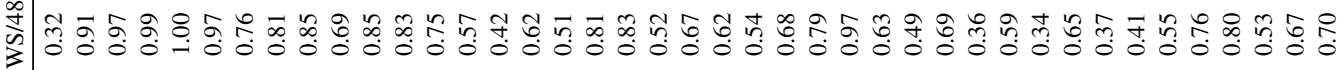

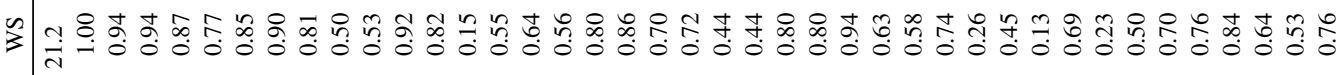

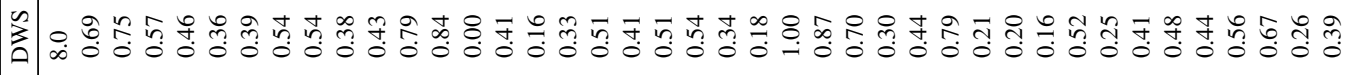

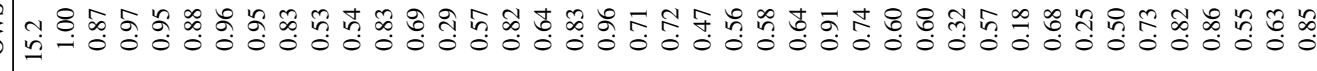

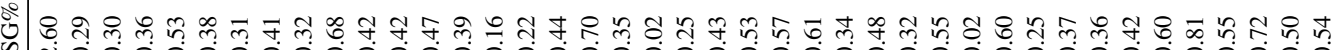

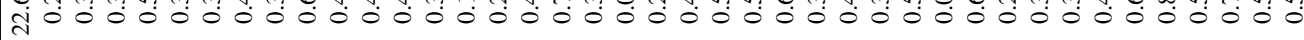

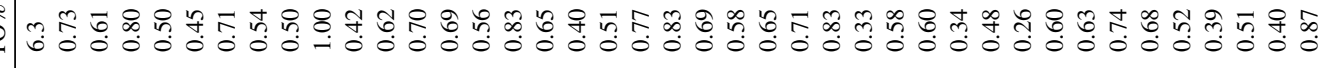

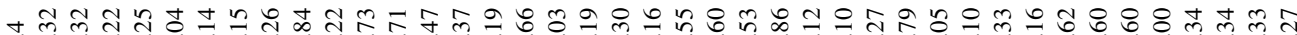

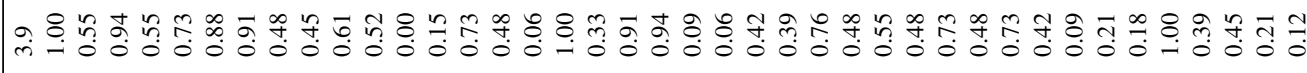

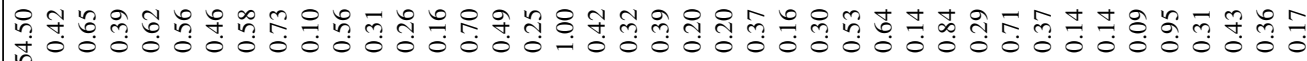

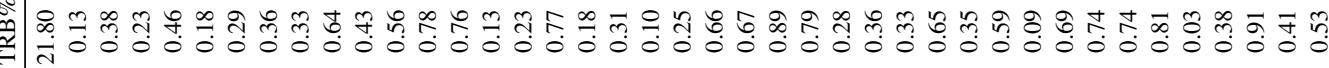

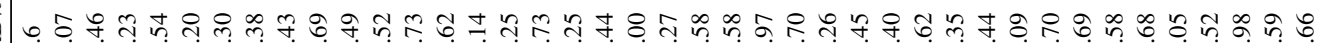

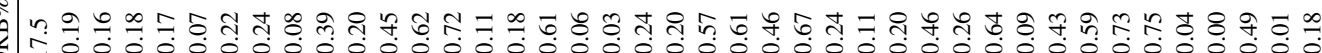
0 -

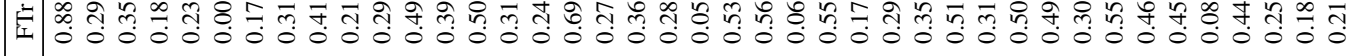

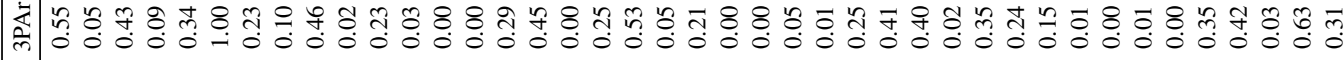

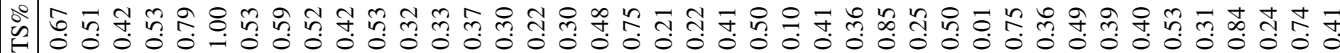

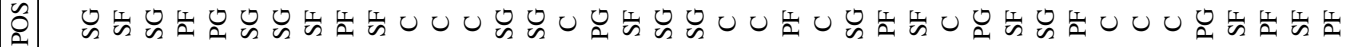

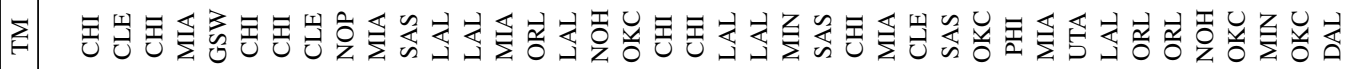
œ

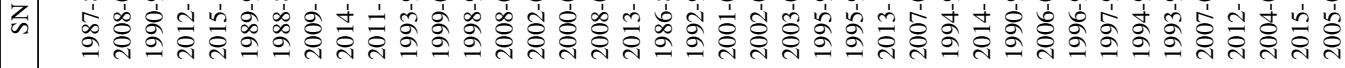
㤅

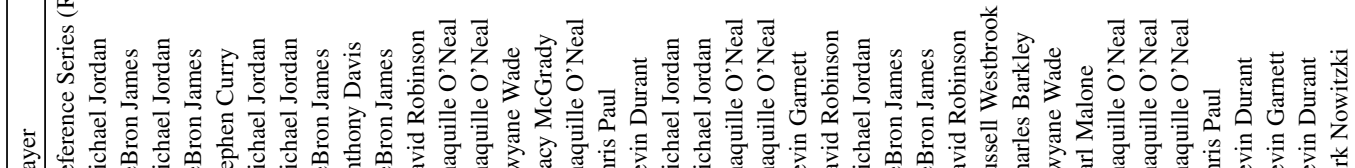

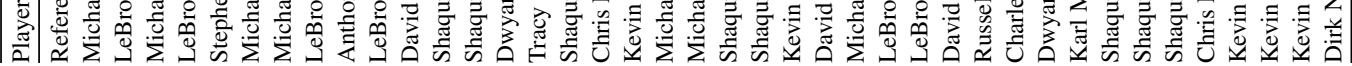




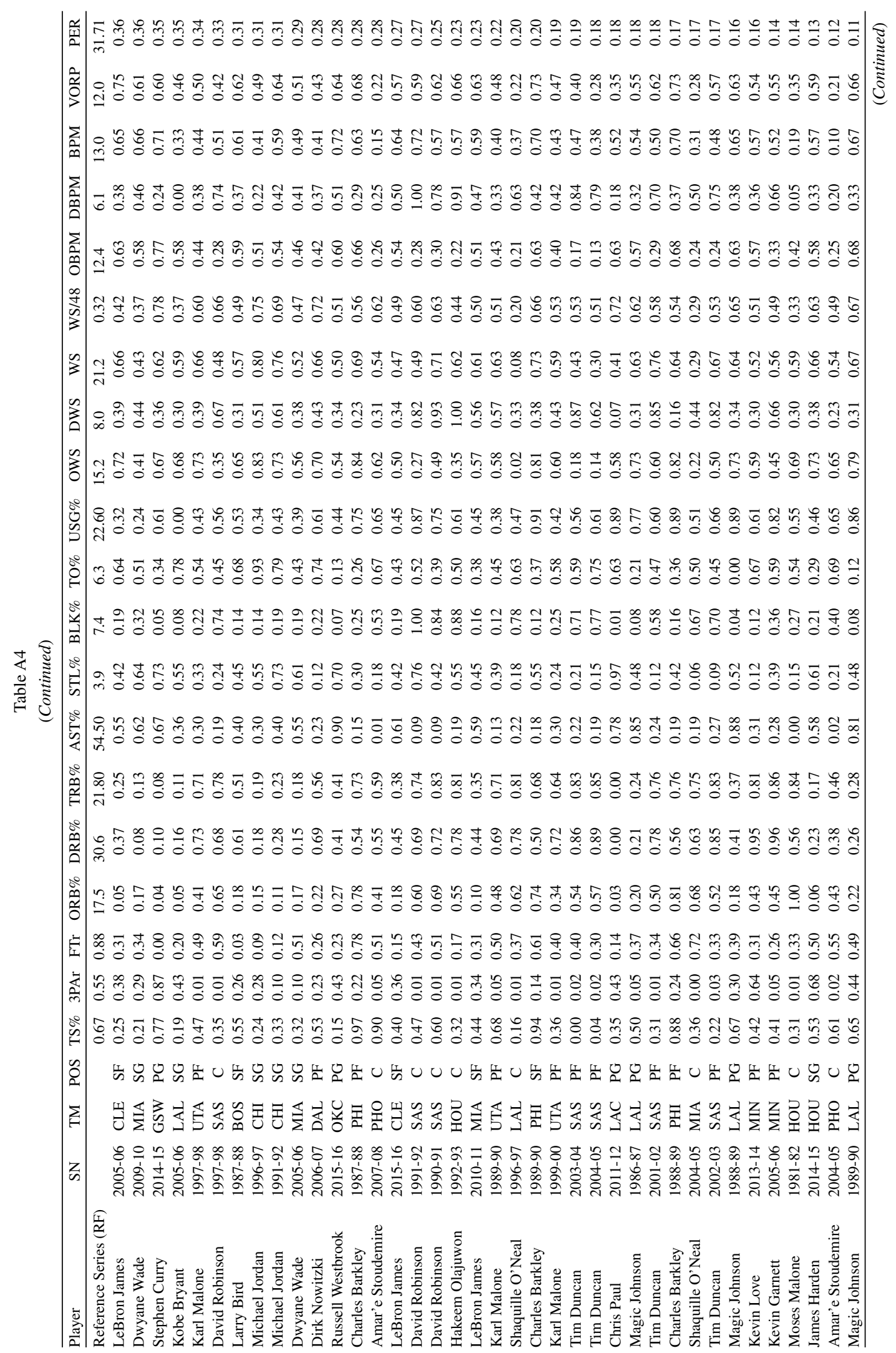




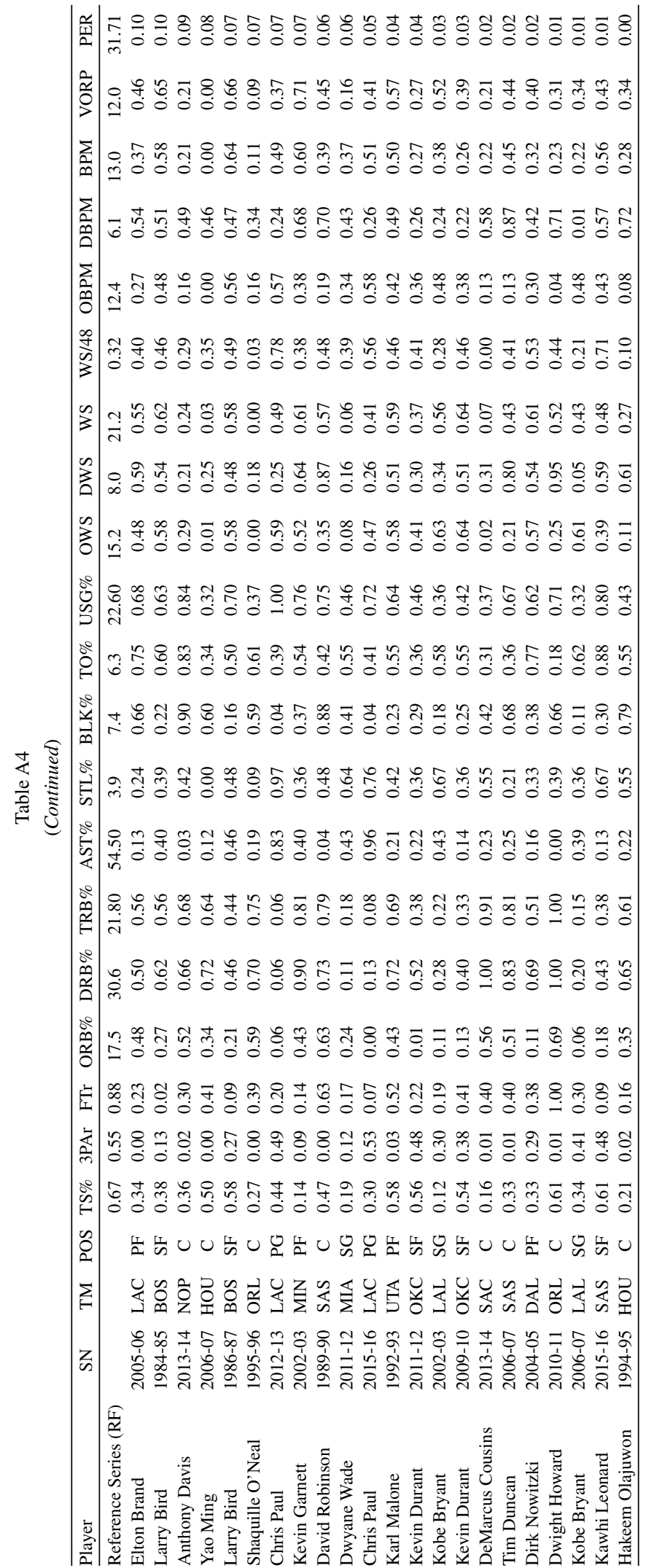




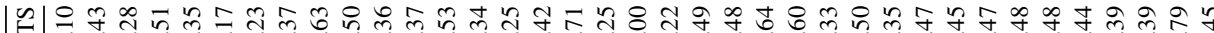

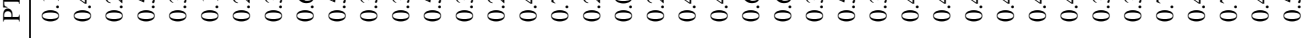

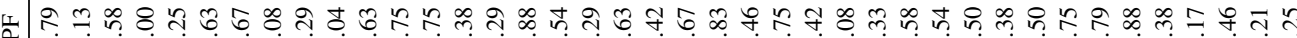

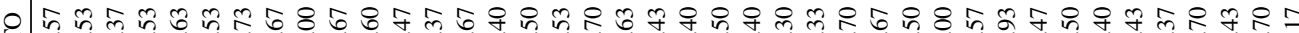

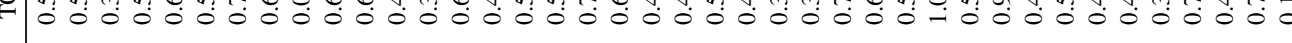

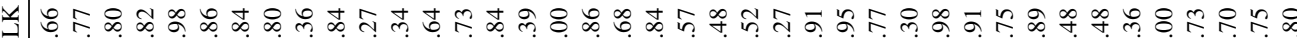

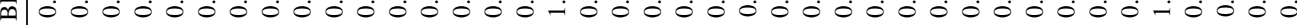

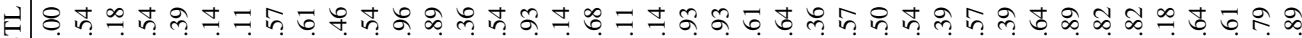

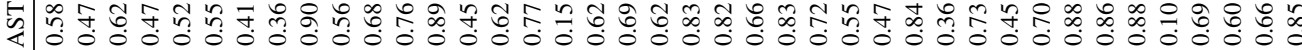

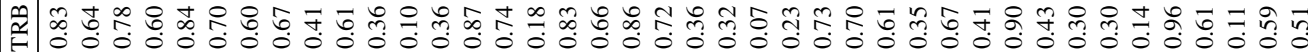

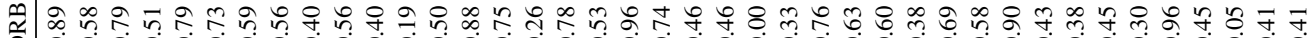

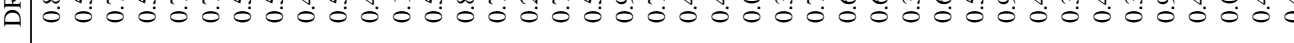

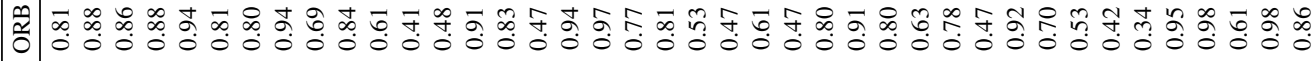

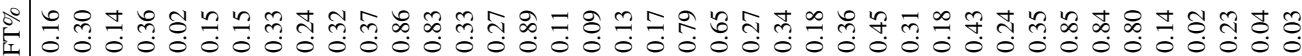
ङ

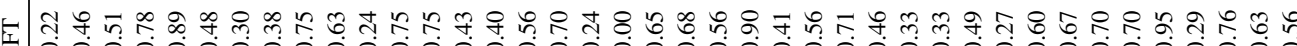
m n

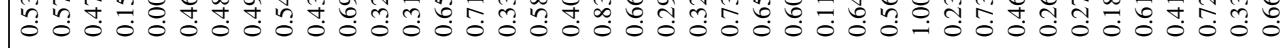

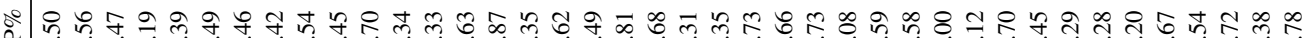

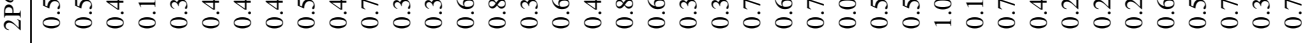

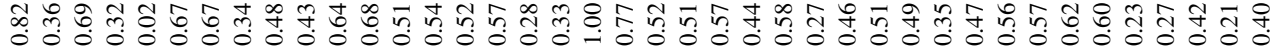

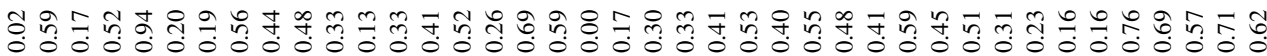

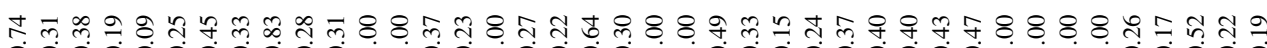
吅制

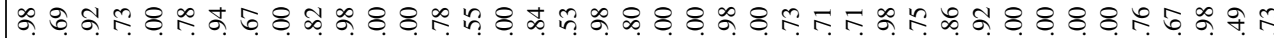

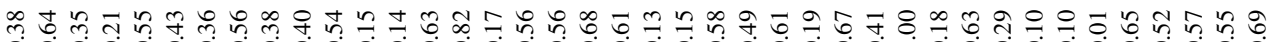

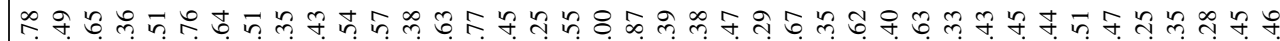
n I 0000000000000000000000000000000000000000

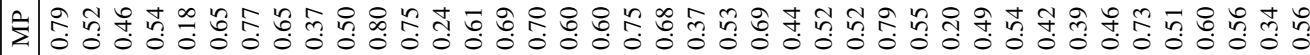

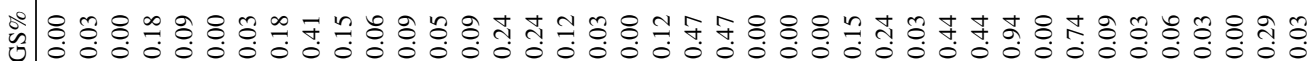

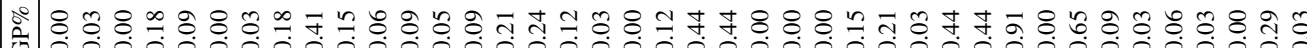

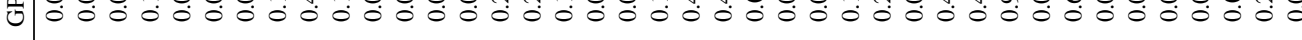

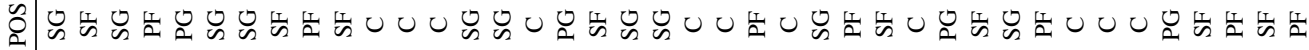

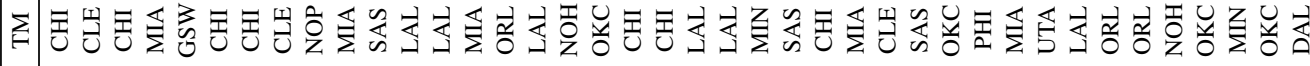
कo

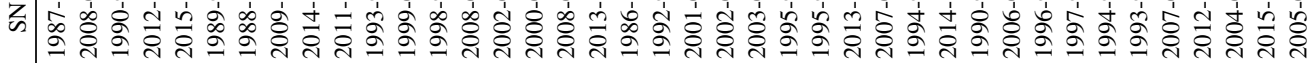

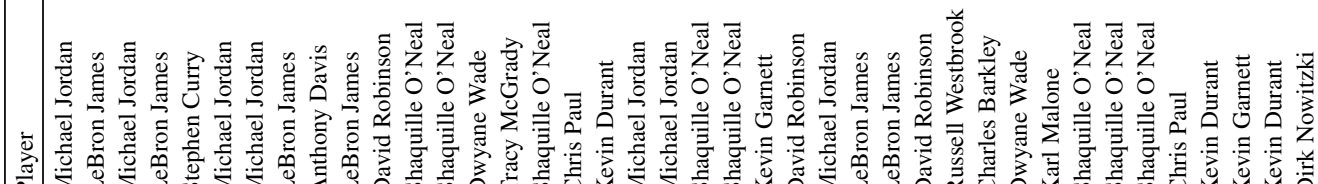




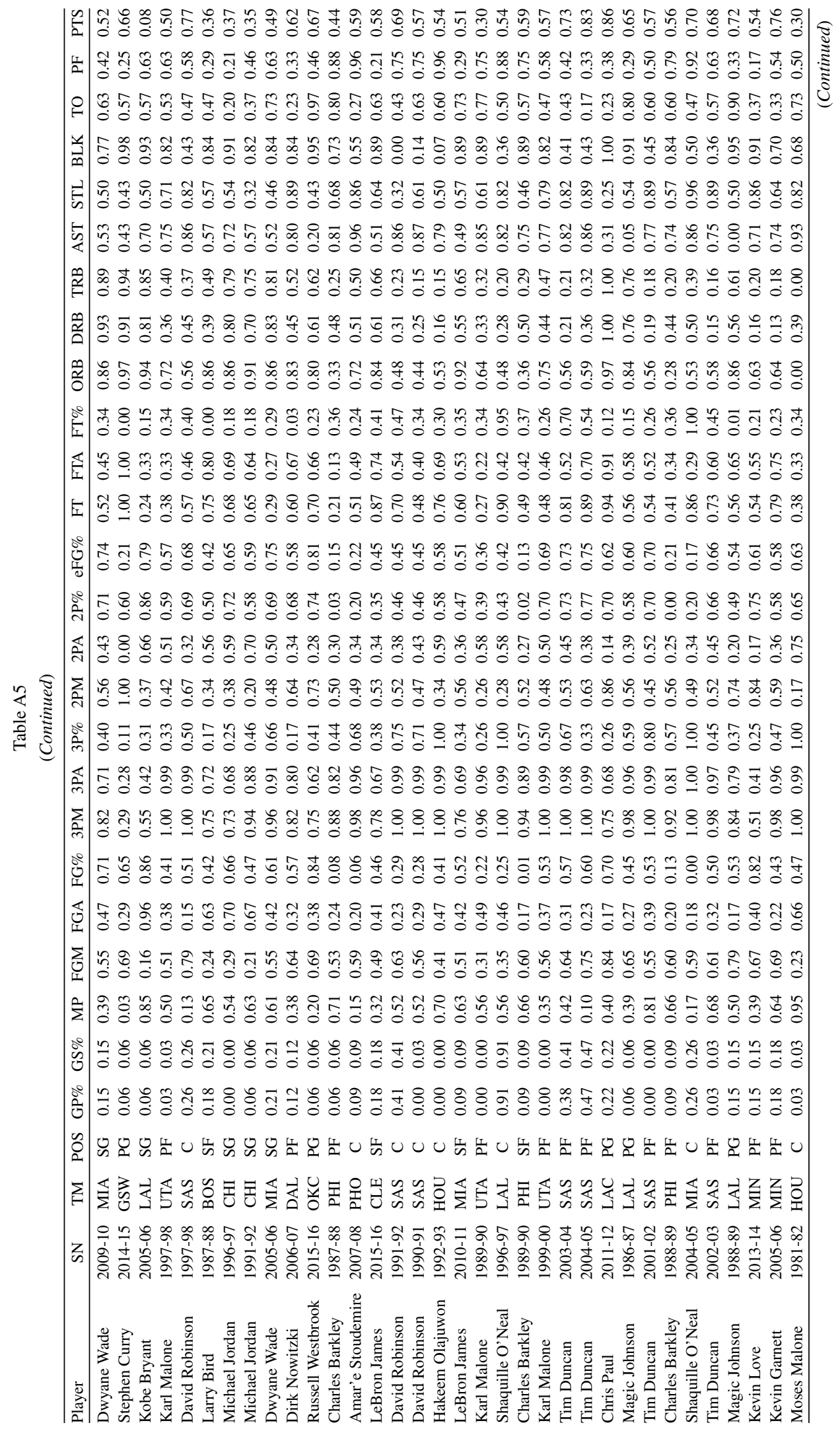




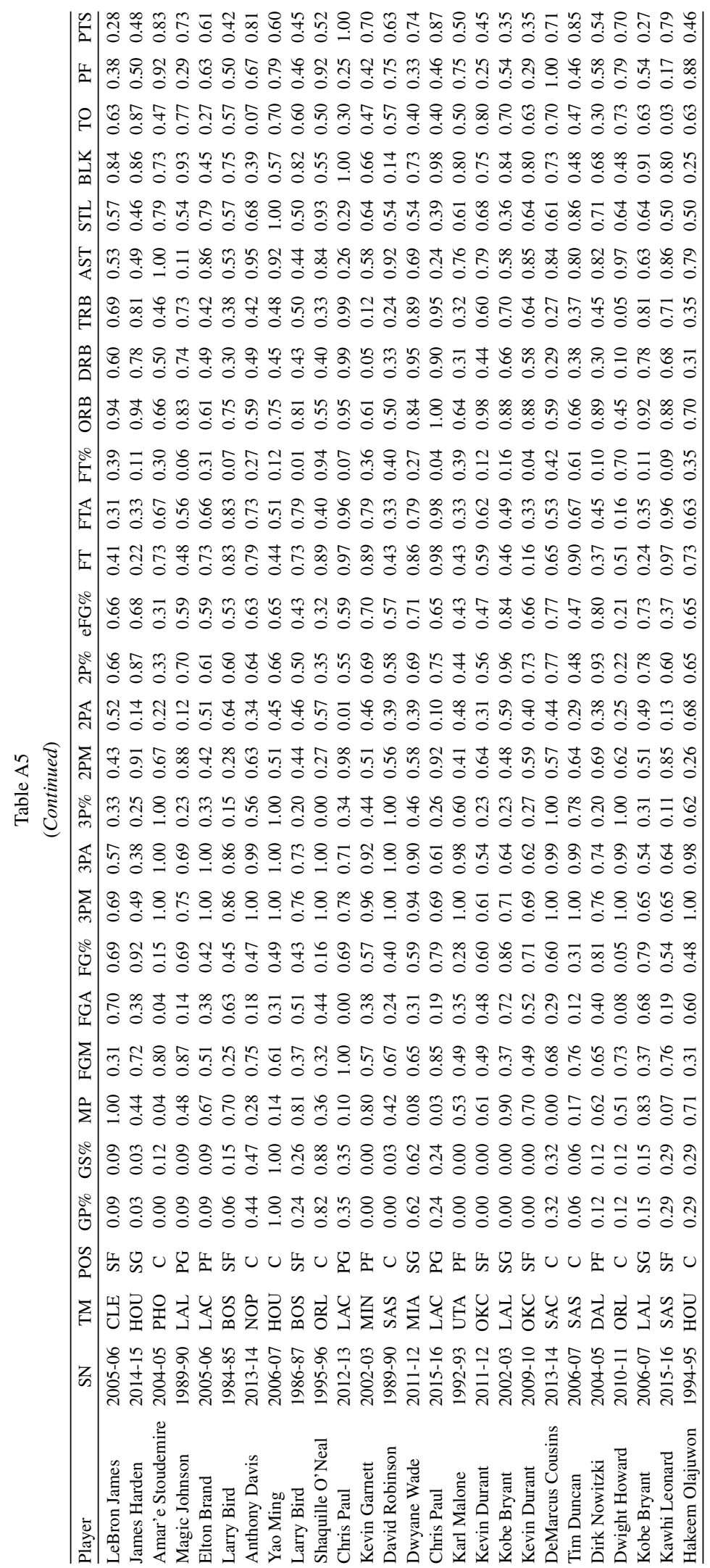


|필

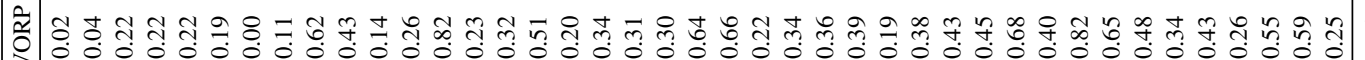

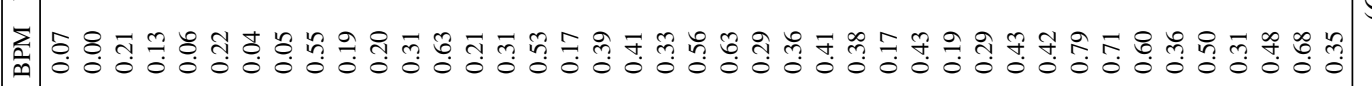

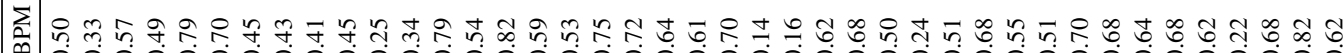

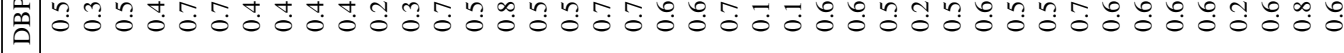

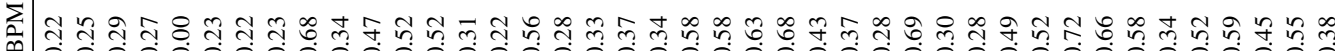
辛

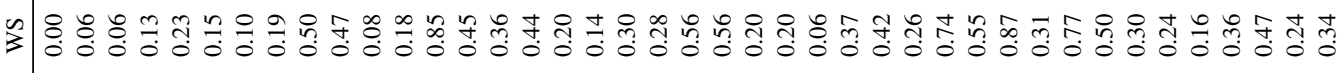

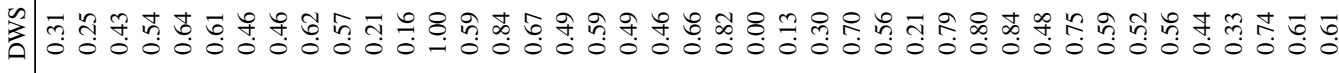

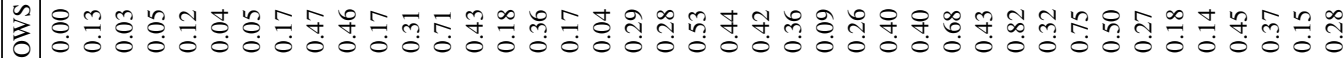

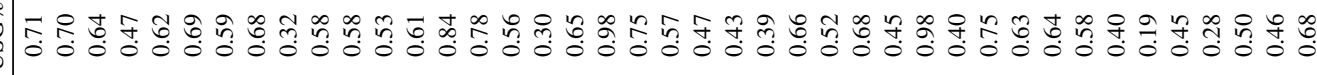

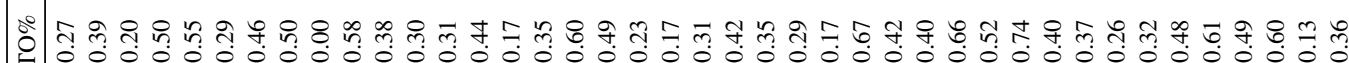

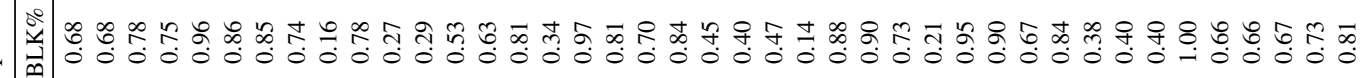

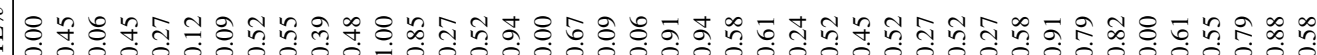

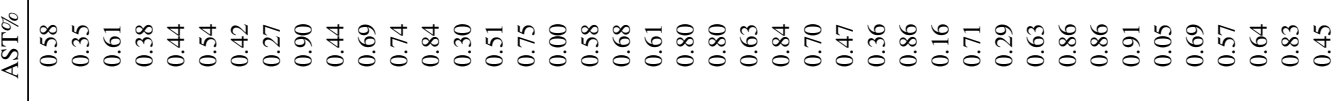

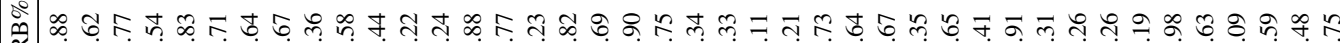

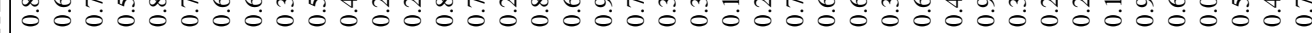

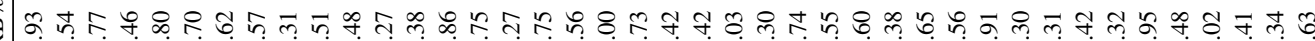

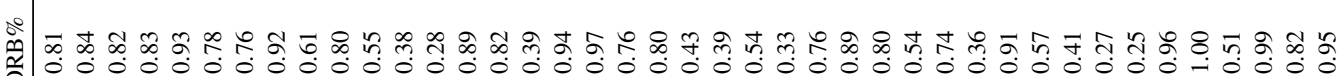

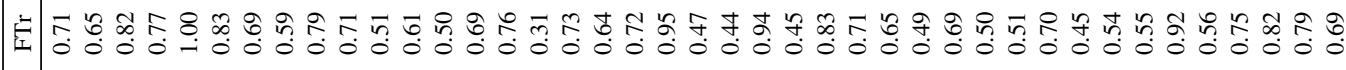

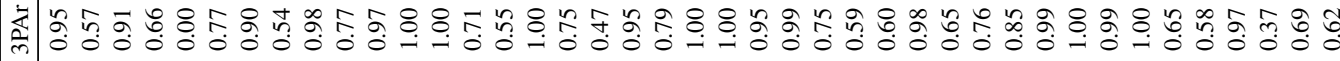

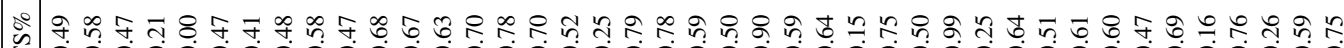

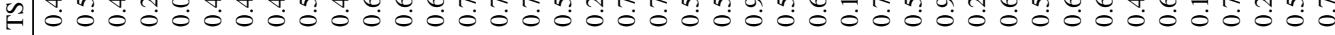

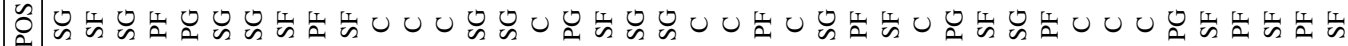

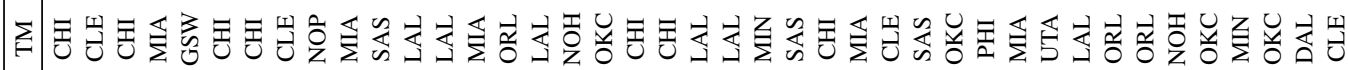
我可 乙

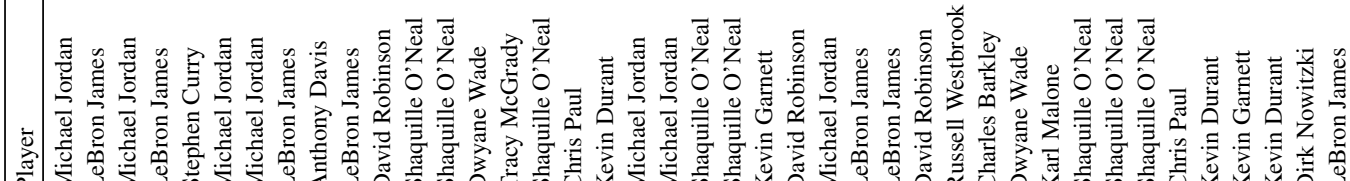




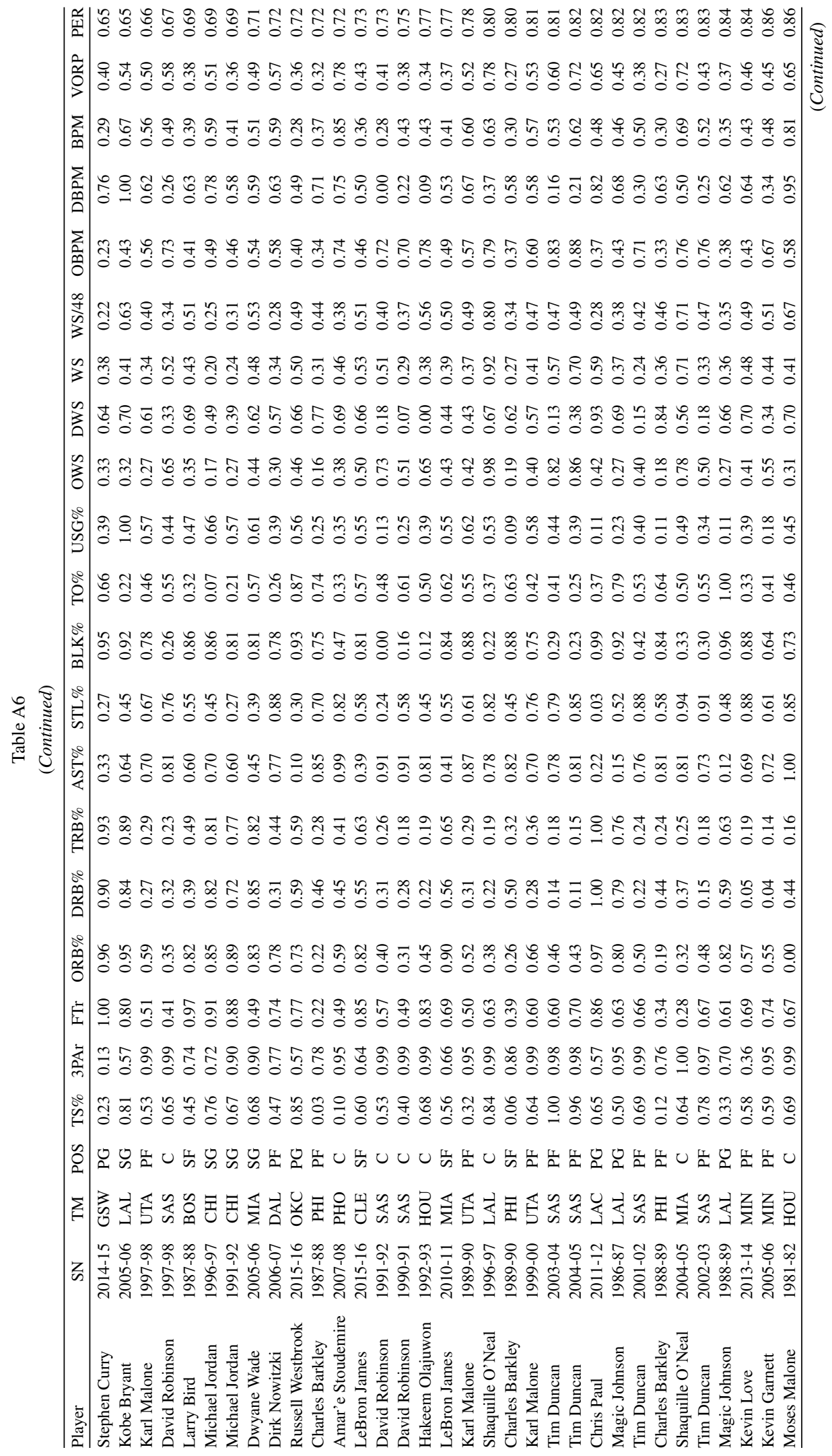




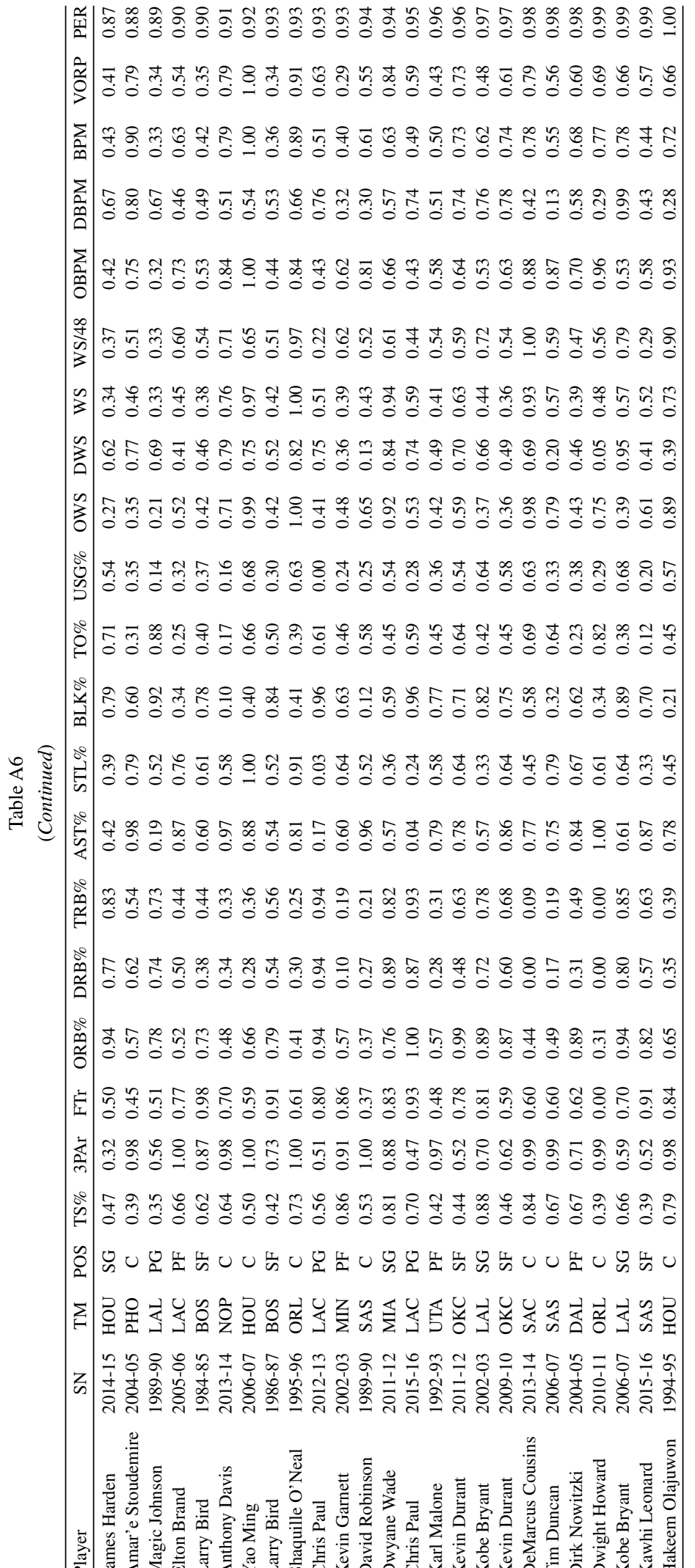




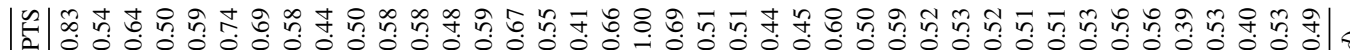
L

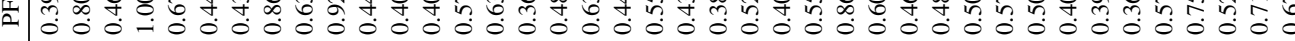

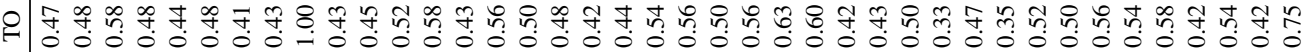

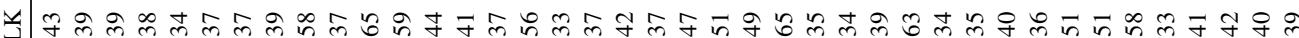

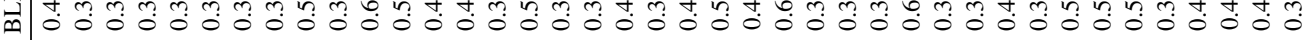

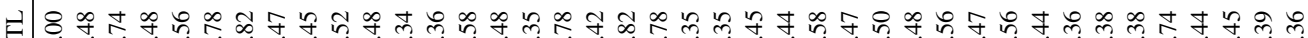
E - 000000000000000000000000000000000000000

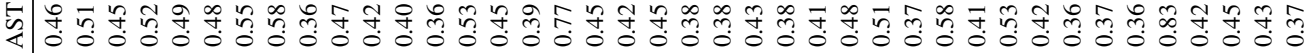

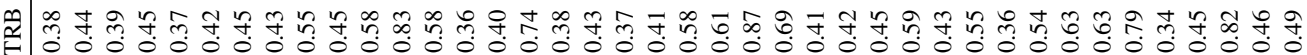

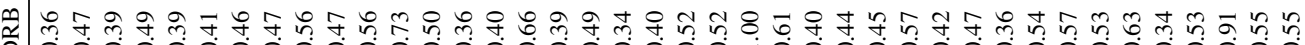
00000000000000000000

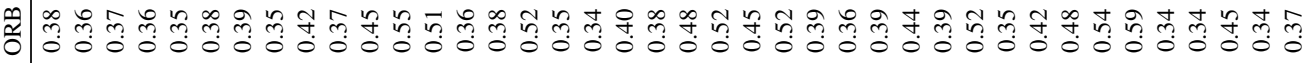

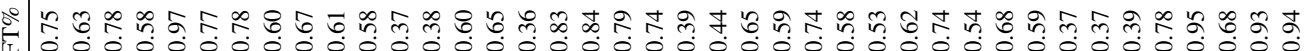

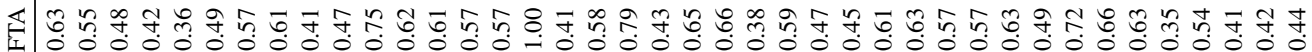

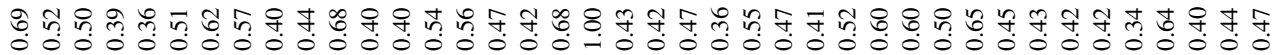

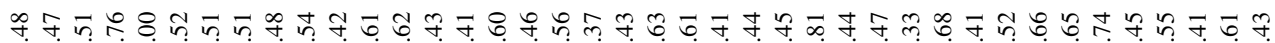
of

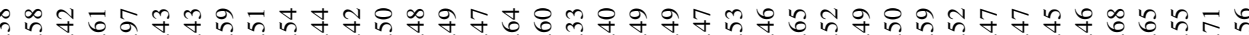

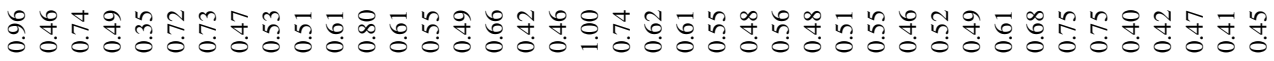

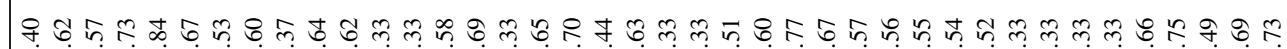
- 00000000000000000000000000000000

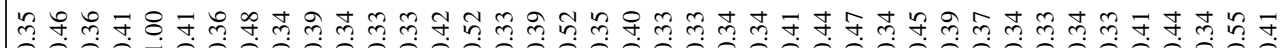

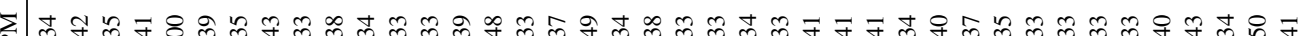

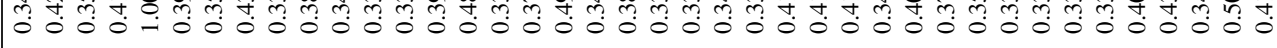

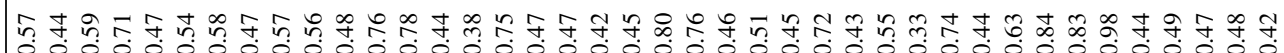

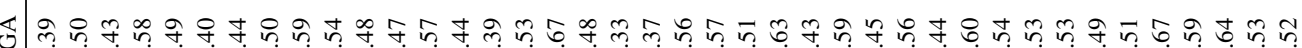

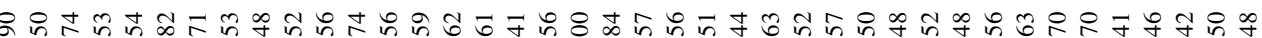

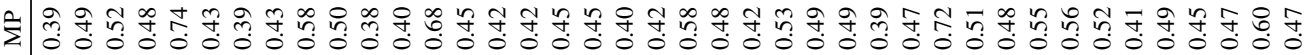

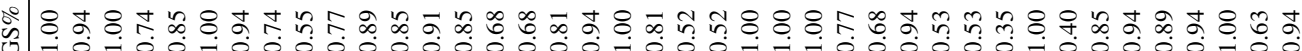

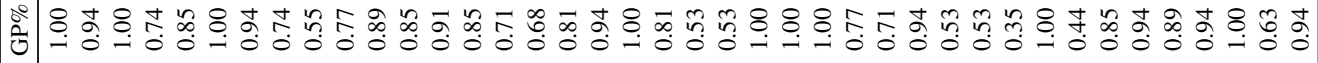

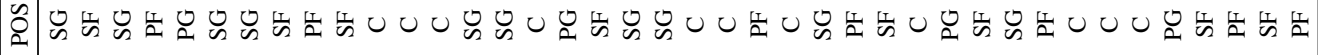

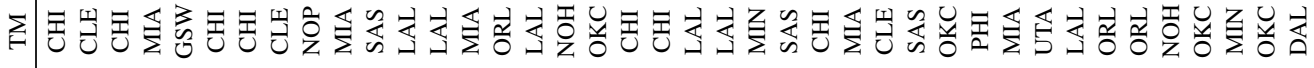
कo Z

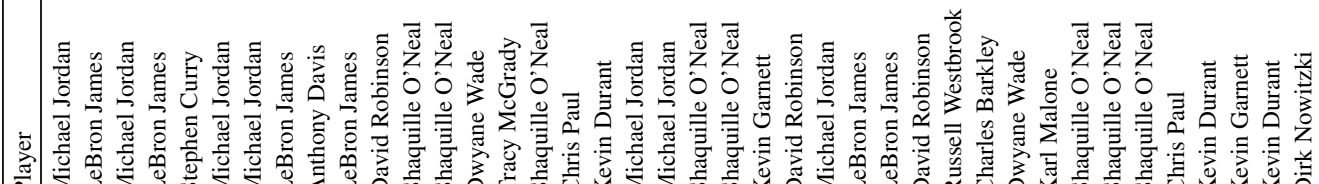




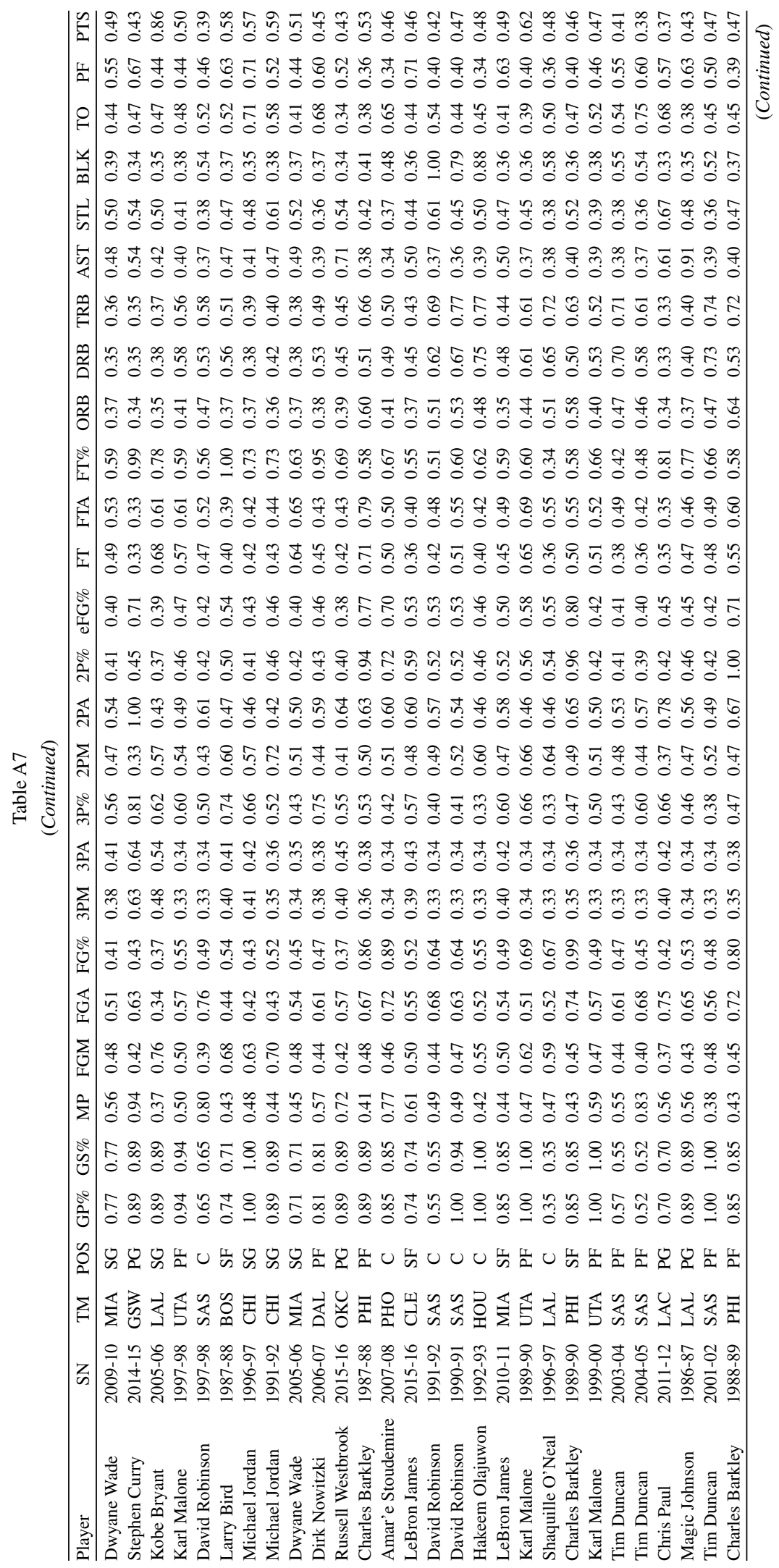




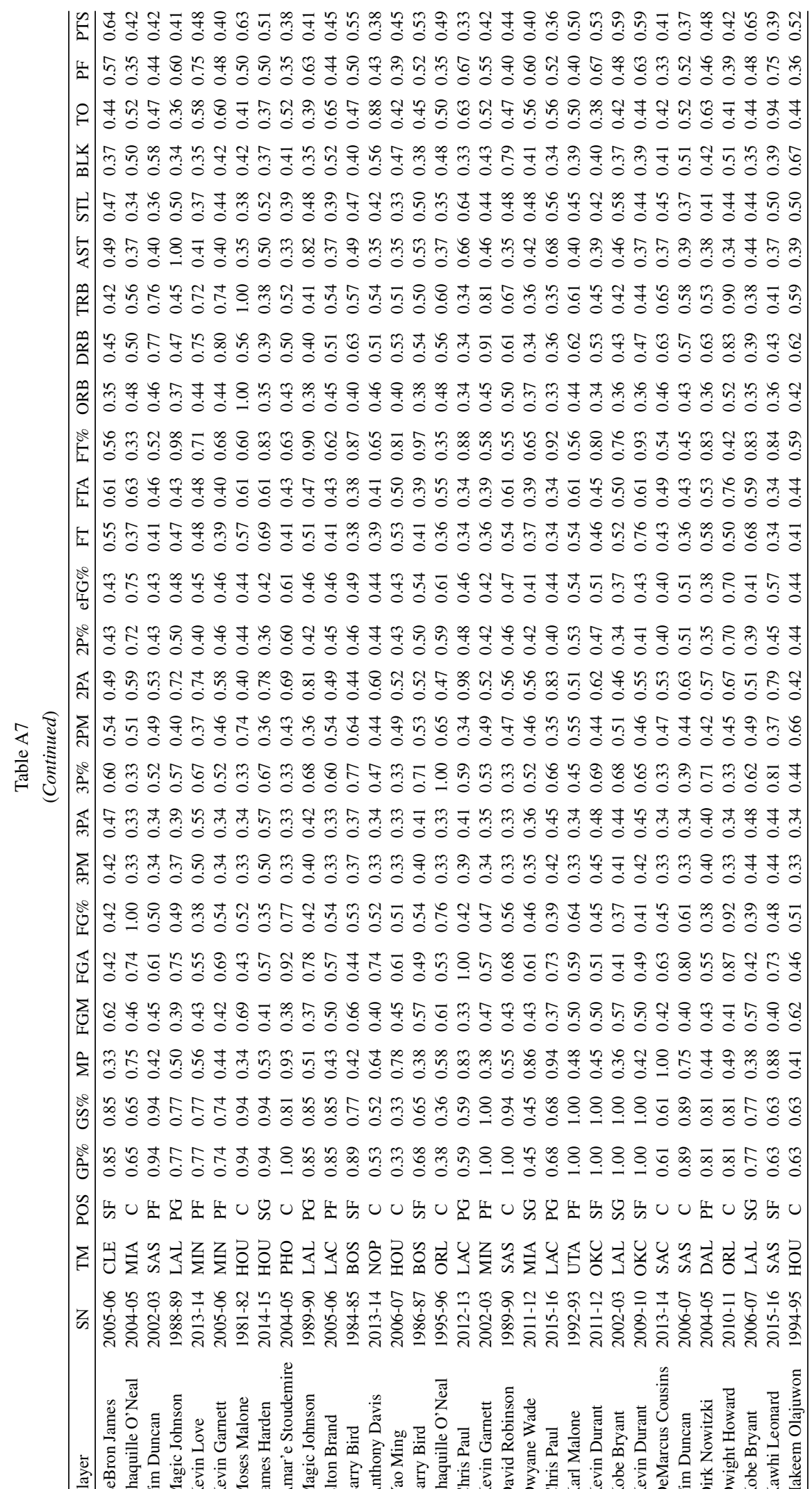




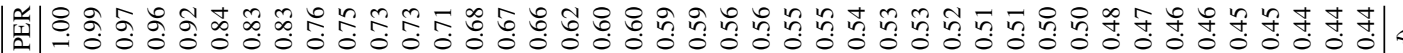

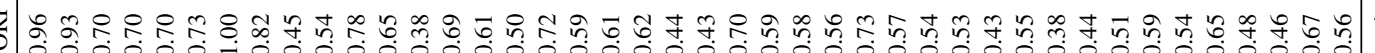

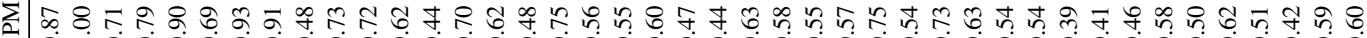

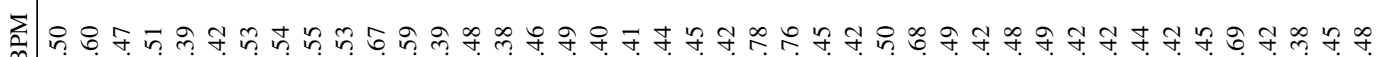

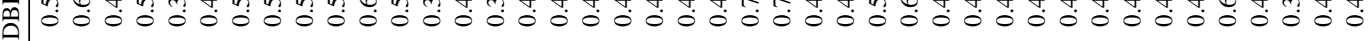

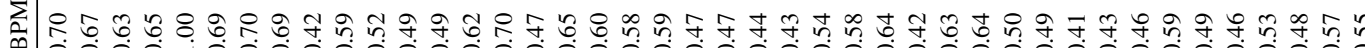

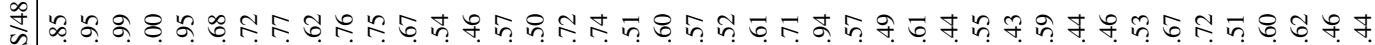

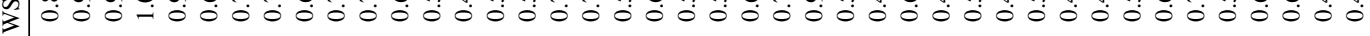

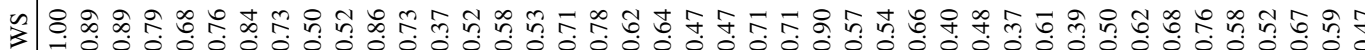

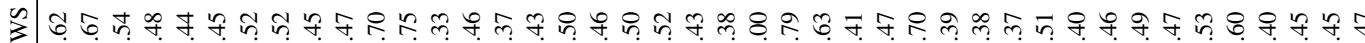

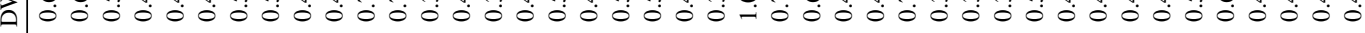

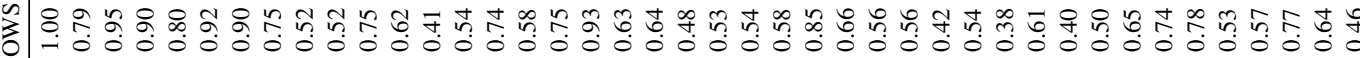

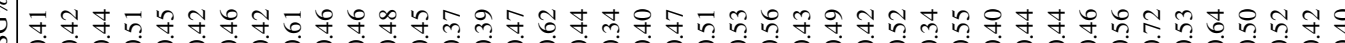

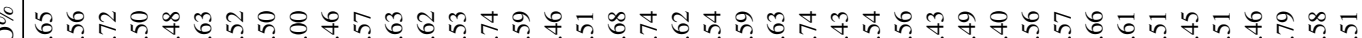

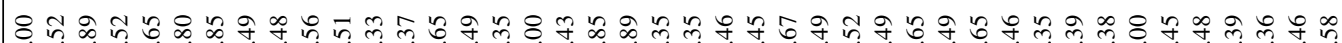

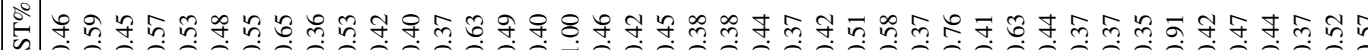

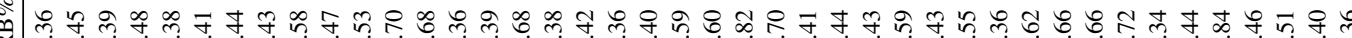

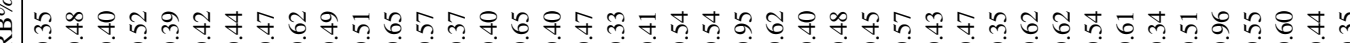

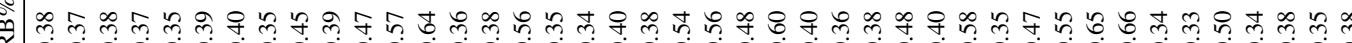

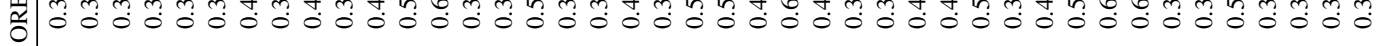

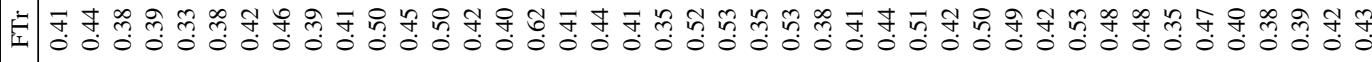

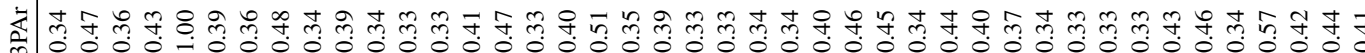

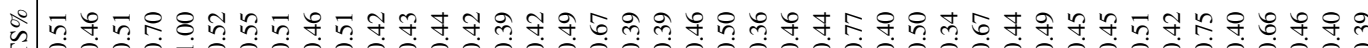

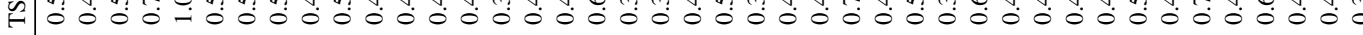

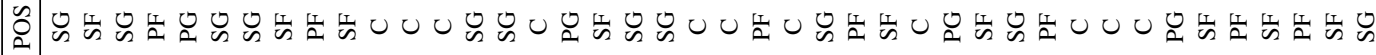

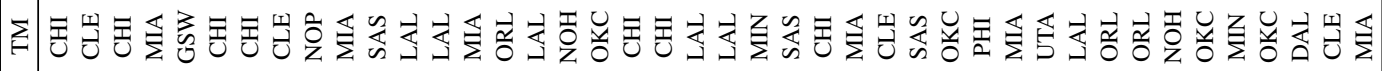
冓 孔

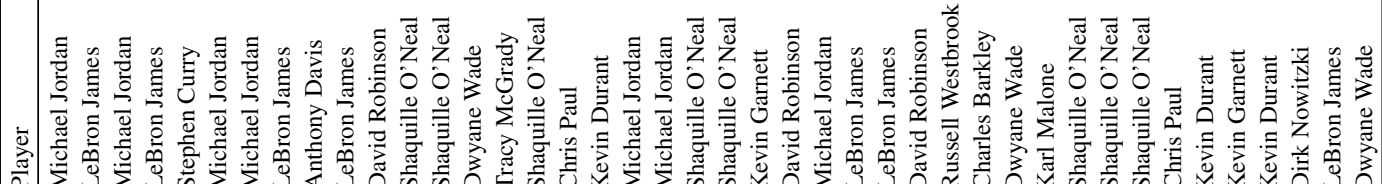


Table A9

Grey relational grades and rankings

\begin{tabular}{|c|c|c|c|c|c|c|c|c|c|}
\hline Player & SN & TM & POS & Traditional & Rank & Advanced & Rank & Overall & Rank \\
\hline Stephen Curry & $2015-16$ & GSW & PG & $62.19 \%$ & 1 & $63.37 \%$ & 2 & $62.72 \%$ & 1 \\
\hline Michael Jordan & $1987-88$ & $\mathrm{CHI}$ & SG & $57.70 \%$ & 5 & $63.98 \%$ & 1 & $60.49 \%$ & 2 \\
\hline Michael Jordan & $1988-89$ & $\mathrm{CHI}$ & SG & $55.90 \%$ & 15 & $61.61 \%$ & 4 & $58.43 \%$ & 3 \\
\hline LeBron James & $2012-13$ & MIA & $\mathrm{PF}$ & $55.93 \%$ & 14 & $60.93 \%$ & 5 & $58.16 \%$ & 4 \\
\hline LeBron James & 2008-09 & CLE & SF & $53.88 \%$ & 36 & $63.33 \%$ & 3 & $58.08 \%$ & 5 \\
\hline Michael Jordan & $1990-91$ & $\mathrm{CHI}$ & SG & $55.60 \%$ & 19 & $60.74 \%$ & 6 & $57.88 \%$ & 6 \\
\hline Charles Barkley & $1987-88$ & PHI & $\mathrm{PF}$ & $58.72 \%$ & 2 & $55.19 \%$ & 21 & $57.15 \%$ & 7 \\
\hline Charles Barkley & $1989-90$ & PHI & SF & $57.32 \%$ & 7 & $56.33 \%$ & 17 & $56.88 \%$ & 8 \\
\hline Dwight Howard & 2010-11 & ORL & $\mathrm{C}$ & $56.98 \%$ & 9 & $56.65 \%$ & 15 & $56.84 \%$ & 9 \\
\hline David Robinson & $1995-96$ & SAS & $\mathrm{C}$ & $55.00 \%$ & 22 & $58.85 \%$ & 9 & $56.71 \%$ & 10 \\
\hline Michael Jordan & $1989-90$ & $\mathrm{CHI}$ & SG & $56.39 \%$ & 10 & $56.96 \%$ & 14 & $56.64 \%$ & 11 \\
\hline Charles Barkley & $1988-89$ & PHI & $\mathrm{PF}$ & $57.30 \%$ & 8 & $55.59 \%$ & 18 & $56.54 \%$ & 12 \\
\hline David Robinson & 1993-94 & SAS & $\mathrm{C}$ & $54.00 \%$ & 31 & $59.26 \%$ & 7 & $56.34 \%$ & 13 \\
\hline Kevin Garnett & 2003-04 & MIN & $\mathrm{PF}$ & $54.06 \%$ & 29 & $59.12 \%$ & 8 & $56.31 \%$ & 14 \\
\hline Shaquille O'Neal & 1999-00 & LAL & $\mathrm{C}$ & $55.32 \%$ & 21 & $57.31 \%$ & 13 & $56.20 \%$ & 15 \\
\hline LeBron James & $2009-10$ & CLE & SF & $53.42 \%$ & 45 & $58.63 \%$ & 11 & $55.74 \%$ & 17 \\
\hline Stephen Curry & 2014-15 & GSW & PG & $57.92 \%$ & 4 & $52.26 \%$ & 31 & $55.40 \%$ & 18 \\
\hline Chris Paul & 2008-09 & $\mathrm{NOH}$ & PG & $52.11 \%$ & 65 & $58.74 \%$ & 10 & $55.06 \%$ & 19 \\
\hline Shaquille O'Neal & 1993-94 & ORL & $\mathrm{C}$ & $57.48 \%$ & 6 & $51.97 \%$ & 36 & $55.03 \%$ & 20 \\
\hline David Robinson & 1991-92 & SAS & $\mathrm{C}$ & $52.33 \%$ & 61 & $58.28 \%$ & 12 & $54.97 \%$ & 21 \\
\hline Kevin Durant & 2013-14 & $\mathrm{OKC}$ & SF & $55.96 \%$ & 13 & $53.68 \%$ & 26 & $54.94 \%$ & 22 \\
\hline Hakeem Olajuwon & $1992-93$ & $\mathrm{HOU}$ & $\mathrm{C}$ & $54.02 \%$ & 30 & $55.41 \%$ & 19 & $54.64 \%$ & 23 \\
\hline Michael Jordan & $1986-87$ & $\mathrm{CHI}$ & SG & $58.45 \%$ & 3 & $49.79 \%$ & 54 & $54.60 \%$ & 24 \\
\hline Kevin Garnett & 2004-05 & MIN & $\mathrm{PF}$ & $53.83 \%$ & 37 & $55.30 \%$ & 20 & $54.48 \%$ & 25 \\
\hline David Robinson & 1994-95 & SAS & $\mathrm{C}$ & $54.40 \%$ & 27 & $54.50 \%$ & 24 & $54.44 \%$ & 26 \\
\hline Kevin Durant & $2012-13$ & $\mathrm{OKC}$ & SF & $56.01 \%$ & 12 & $52.36 \%$ & 30 & $54.39 \%$ & 27 \\
\hline Michael Jordan & $1995-96$ & $\mathrm{CHI}$ & SG & $53.73 \%$ & 41 & $55.13 \%$ & 22 & $54.35 \%$ & 28 \\
\hline David Robinson & $1989-90$ & SAS & $\mathrm{C}$ & $54.11 \%$ & 28 & $53.16 \%$ & 27 & $53.69 \%$ & 29 \\
\hline Chris Paul & 2007-08 & $\mathrm{NOH}$ & PG & $52.59 \%$ & 59 & $54.62 \%$ & 23 & $53.49 \%$ & 30 \\
\hline LeBron James & 2013-14 & MIA & $\mathrm{PF}$ & $55.67 \%$ & 16 & $50.45 \%$ & 50 & $53.35 \%$ & 31 \\
\hline Magic Johnson & $1988-89$ & LAL & PG & $53.96 \%$ & 32 & $51.83 \%$ & 37 & $53.02 \%$ & 34 \\
\hline Karl Malone & $1989-90$ & UTA & $\mathrm{PF}$ & $56.38 \%$ & 11 & $48.43 \%$ & 69 & $52.85 \%$ & 35 \\
\hline Kawhi Leonard & $2015-16$ & SAS & SF & $54.72 \%$ & 23 & $50.27 \%$ & 51 & $52.74 \%$ & 36 \\
\hline Shaquille O'Neal & 2000-01 & LAL & $\mathrm{C}$ & $53.75 \%$ & 39 & $51.36 \%$ & 39 & $52.69 \%$ & 37 \\
\hline Michael Jordan & $1992-93$ & $\mathrm{CHI}$ & SG & $53.14 \%$ & 48 & $52.09 \%$ & 34 & $52.67 \%$ & 38 \\
\hline LeBron James & 2011-12 & MIA & SF & $52.88 \%$ & 52 & $52.36 \%$ & 29 & $52.65 \%$ & 39 \\
\hline Kevin Garnett & $2002-03$ & MIN & $\mathrm{PF}$ & $53.12 \%$ & 50 & $51.74 \%$ & 38 & $52.51 \%$ & 40 \\
\hline Anthony Davis & $2014-15$ & NOP & $\mathrm{PF}$ & $51.39 \%$ & 72 & $53.89 \%$ & 25 & $52.50 \%$ & 41 \\
\hline Amar'e Stoudemire & 2007-08 & $\mathrm{PHO}$ & $\mathrm{C}$ & $55.49 \%$ & 20 & $48.47 \%$ & 68 & $52.37 \%$ & 42 \\
\hline Moses Malone & $1981-82$ & $\mathrm{HOU}$ & $\mathrm{C}$ & $55.62 \%$ & 17 & $48.17 \%$ & 75 & $52.31 \%$ & 43 \\
\hline Tim Duncan & 2001-02 & SAS & $\mathrm{PF}$ & $52.28 \%$ & 63 & $52.17 \%$ & 33 & $52.23 \%$ & 44 \\
\hline Chris Paul & $2012-13$ & LAC & PG & $52.96 \%$ & 51 & $51.16 \%$ & 43 & $52.16 \%$ & 45 \\
\hline Tim Duncan & 2002-03 & SAS & $\mathrm{PF}$ & $51.98 \%$ & 66 & $52.22 \%$ & 32 & $52.09 \%$ & 46 \\
\hline Kevin Garnett & $2005-06$ & MIN & $\mathrm{PF}$ & $51.60 \%$ & 69 & $52.46 \%$ & 28 & $51.98 \%$ & 47 \\
\hline Karl Malone & $1992-93$ & UTA & $\mathrm{PF}$ & $53.93 \%$ & 33 & $49.45 \%$ & 57 & $51.94 \%$ & 48 \\
\hline Dirk Nowitzki & $2005-06$ & DAL & $\mathrm{PF}$ & $53.75 \%$ & 38 & $49.53 \%$ & 56 & $51.87 \%$ & 49 \\
\hline Karl Malone & $1996-97$ & UTA & PF & $52.65 \%$ & 58 & $50.77 \%$ & 46 & $51.81 \%$ & 50 \\
\hline
\end{tabular}


Table A9

(Continued)

\begin{tabular}{|c|c|c|c|c|c|c|c|c|c|}
\hline Player & SN & TM & POS & Traditional & Rank & Advanced & Rank & Overall & Rank \\
\hline Charles Barkley & $1990-91$ & PHI & $\mathrm{SF}$ & $52.68 \%$ & 57 & $50.71 \%$ & 47 & $51.80 \%$ & 51 \\
\hline Shaquille O'Neal & 1994-95 & ORL & $\mathrm{C}$ & $54.59 \%$ & 25 & $48.28 \%$ & 72 & $51.79 \%$ & 52 \\
\hline James Harden & 2014-15 & $\mathrm{HOU}$ & SG & $53.70 \%$ & 42 & $49.11 \%$ & 60 & $51.66 \%$ & 53 \\
\hline Larry Bird & $1987-88$ & BOS & SF & $53.89 \%$ & 35 & $48.57 \%$ & 65 & $51.52 \%$ & 54 \\
\hline Tim Duncan & 2006-07 & SAS & $\mathrm{C}$ & $51.97 \%$ & 67 & $50.60 \%$ & 48 & $51.36 \%$ & 55 \\
\hline Michael Jordan & $1996-97$ & $\mathrm{CHI}$ & SG & $53.13 \%$ & 49 & $49.03 \%$ & 61 & $51.31 \%$ & 56 \\
\hline Michael Jordan & $1991-92$ & $\mathrm{CHI}$ & SG & $52.32 \%$ & 62 & $50.00 \%$ & 53 & $51.29 \%$ & 57 \\
\hline Kevin Durant & $2015-16$ & $\mathrm{OKC}$ & SF & $53.65 \%$ & 43 & $48.23 \%$ & 73 & $51.24 \%$ & 58 \\
\hline Karl Malone & $1997-98$ & UTA & $\mathrm{PF}$ & $52.70 \%$ & 56 & $49.22 \%$ & 59 & $51.15 \%$ & 59 \\
\hline Larry Bird & $1984-85$ & BOS & $\mathrm{SF}$ & $53.34 \%$ & 46 & $48.37 \%$ & 70 & $51.13 \%$ & 60 \\
\hline Dirk Nowitzki & 2006-07 & DAL & $\mathrm{PF}$ & $52.82 \%$ & 54 & $48.87 \%$ & 62 & $51.06 \%$ & 61 \\
\hline Dwyane Wade & 2008-09 & MIA & SG & $51.34 \%$ & 73 & $50.54 \%$ & 49 & $50.98 \%$ & 62 \\
\hline Tracy McGrady & 2002-03 & ORL & SG & $51.00 \%$ & 78 & $50.82 \%$ & 45 & $50.92 \%$ & 63 \\
\hline Magic Johnson & $1986-87$ & LAL & PG & $52.47 \%$ & 60 & $48.69 \%$ & 63 & $50.79 \%$ & 64 \\
\hline Shaquille O'Neal & $1998-99$ & LAL & $\mathrm{C}$ & $53.28 \%$ & 47 & $47.66 \%$ & 79 & $50.78 \%$ & 65 \\
\hline LeBron James & 2007-08 & CLE & SF & $50.33 \%$ & 86 & $51.22 \%$ & 42 & $50.72 \%$ & 66 \\
\hline David Robinson & $1997-98$ & SAS & $\mathrm{C}$ & $50.29 \%$ & 87 & $51.15 \%$ & 44 & $50.67 \%$ & 67 \\
\hline Larry Bird & $1986-87$ & BOS & $\mathrm{SF}$ & $52.12 \%$ & 64 & $48.62 \%$ & 64 & $50.57 \%$ & 68 \\
\hline Kevin Durant & $2009-10$ & $\mathrm{OKC}$ & $\mathrm{SF}$ & $54.45 \%$ & 26 & $45.23 \%$ & 92 & $50.35 \%$ & 69 \\
\hline Chris Paul & 2011-12 & LAC & PG & $50.94 \%$ & 79 & $49.59 \%$ & 55 & $50.34 \%$ & 70 \\
\hline Russell Westbrook & $2015-16$ & $\mathrm{OKC}$ & PG & $51.19 \%$ & 76 & $49.22 \%$ & 58 & $50.31 \%$ & 71 \\
\hline Shaquille O’Neal & 2004-05 & MIA & $\mathrm{C}$ & $52.79 \%$ & 55 & $46.94 \%$ & 83 & $50.19 \%$ & 72 \\
\hline Amar'e Stoudemire & 2004-05 & $\mathrm{PHO}$ & $\mathrm{C}$ & $53.73 \%$ & 40 & $45.47 \%$ & 91 & $50.06 \%$ & 73 \\
\hline Chris Paul & $2015-16$ & LAC & PG & $51.95 \%$ & 68 & $47.56 \%$ & 80 & $50.00 \%$ & 74 \\
\hline LeBron James & $2005-06$ & CLE & SF & $51.17 \%$ & 77 & $48.47 \%$ & 67 & $49.97 \%$ & 75 \\
\hline Tim Duncan & 2004-05 & SAS & $\mathrm{PF}$ & $49.47 \%$ & 90 & $50.24 \%$ & 52 & $49.81 \%$ & 76 \\
\hline Dirk Nowitzki & 2004-05 & DAL & $\mathrm{PF}$ & $51.57 \%$ & 70 & $47.49 \%$ & 81 & $49.75 \%$ & 77 \\
\hline Shaquille O'Neal & 2001-02 & LAL & $\mathrm{C}$ & $50.57 \%$ & 84 & $48.53 \%$ & 66 & $49.66 \%$ & 78 \\
\hline LeBron James & $2010-11$ & MIA & $\mathrm{SF}$ & $51.21 \%$ & 75 & $47.72 \%$ & 77 & $49.66 \%$ & 79 \\
\hline Tim Duncan & 2003-04 & SAS & $\mathrm{PF}$ & $48.27 \%$ & 95 & $51.34 \%$ & 40 & $49.63 \%$ & 80 \\
\hline Karl Malone & 1999-00 & UTA & $\mathrm{PF}$ & $51.54 \%$ & 71 & $47.22 \%$ & 82 & $49.62 \%$ & 81 \\
\hline Elton Brand & 2005-06 & LAC & $\mathrm{PF}$ & $50.88 \%$ & 80 & $47.75 \%$ & 76 & $49.49 \%$ & 82 \\
\hline Shaquille O'Neal & 2002-03 & LAL & $\mathrm{C}$ & $50.23 \%$ & 88 & $48.20 \%$ & 74 & $49.33 \%$ & 83 \\
\hline Kobe Bryant & 2005-06 & LAL & SG & $52.87 \%$ & 53 & $44.42 \%$ & 93 & $49.12 \%$ & 84 \\
\hline LeBron James & $2015-16$ & CLE & $\mathrm{SF}$ & $50.85 \%$ & 82 & $46.88 \%$ & 84 & $49.08 \%$ & 85 \\
\hline Kevin Durant & 2011-12 & OKC & SF & $53.60 \%$ & 44 & $43.20 \%$ & 96 & $48.98 \%$ & 86 \\
\hline Anthony Davis & 2013-14 & NOP & $\mathrm{C}$ & $49.51 \%$ & 89 & $48.30 \%$ & 71 & $48.97 \%$ & 87 \\
\hline Shaquille O'Neal & $1997-98$ & LAL & $\mathrm{C}$ & $50.85 \%$ & 81 & $45.83 \%$ & 88 & $48.62 \%$ & 88 \\
\hline Kobe Bryant & $2002-03$ & LAL & SG & $51.27 \%$ & 74 & $44.39 \%$ & 94 & $48.21 \%$ & 89 \\
\hline Russell Westbrook & 2014-15 & $\mathrm{OKC}$ & PG & $48.19 \%$ & 96 & $47.72 \%$ & 78 & $47.98 \%$ & 90 \\
\hline Dwyane Wade & 2009-10 & MIA & SG & $48.91 \%$ & 92 & $46.29 \%$ & 86 & $47.74 \%$ & 91 \\
\hline Hakeem Olajuwon & 1994-95 & $\mathrm{HOU}$ & $\mathrm{C}$ & $49.06 \%$ & 91 & $45.77 \%$ & 89 & $47.60 \%$ & 92 \\
\hline DeMarcus Cousins & 2013-14 & SAC & $\mathrm{C}$ & $48.47 \%$ & 93 & $46.23 \%$ & 87 & $47.47 \%$ & 93 \\
\hline Shaquille O’Neal & 1996-97 & LAL & $\mathrm{C}$ & $47.75 \%$ & 97 & $46.75 \%$ & 85 & $47.30 \%$ & 94 \\
\hline Shaquille O'Neal & $1995-96$ & ORL & $\mathrm{C}$ & $50.57 \%$ & 85 & $42.88 \%$ & 97 & $47.15 \%$ & 95 \\
\hline Dwyane Wade & $2005-06$ & MIA & SG & $48.33 \%$ & 94 & $45.57 \%$ & 90 & $47.10 \%$ & 96 \\
\hline Kobe Bryant & 2006-07 & LAL & SG & $50.64 \%$ & 83 & $41.97 \%$ & 98 & $46.79 \%$ & 97 \\
\hline Dwyane Wade & 2006-07 & MIA & SG & $46.58 \%$ & 99 & $44.35 \%$ & 95 & $45.59 \%$ & 98 \\
\hline Dwyane Wade & 2011-12 & MIA & SG & $46.74 \%$ & 98 & $41.75 \%$ & 100 & $44.52 \%$ & 99 \\
\hline Yao Ming & 2006-07 & $\mathrm{HOU}$ & $\mathrm{C}$ & $46.36 \%$ & 100 & $41.97 \%$ & 99 & $44.41 \%$ & 100 \\
\hline
\end{tabular}

